Revista de Derecho

de la Pontificia Universidad Católica de Valparaíso

XXXV (Valparaíso, Chile, 2010, 2 Semestre)

[pp. 325 - 360]

\title{
LA INCIDENCIA DEL DERECHO EN EL CONTROL DE LA INFLACIÓN
}

["Incidence of Law in Inflation Control"]

José Luis Guerrero BeCAR*

Pontificia Universidad Católica de Valparaíso

\begin{abstract}
RESUMEN
La Constitución chilena de 1980 ofrece una serie de normas, cuyo conjunto, por su contenido, conforman la denominada “constitución económica”. Además de una definición sobre el rol de los actores económicos, especialmente el Estado y los particulares, de manera sistemática pero inorgánica se diseñan en ella las bases y los medios de control para que exista una economía monetariamente estable. Por eso, desde la vigencia plena de la Constitución, a partir de 1990, Chile presenta niveles de inflación bajos y regulares, en comparación con épocas precedentes. Este fenómeno se debe en buena medida a una incidencia del Derecho.

Palabras clave: Inflación - Banco Central - Monetarismo - Constitución.
\end{abstract}

\begin{abstract}
The Chilean Constitution of 1980 contains several norms, and, given their content, they altogether make up the so called "economical constitution". Besides giving a definition of the role of the economical agents, especially the State and citizens, the Constitution, systematically, though not organically, designs the grounds and control means to have a stable monetary economy. Therefore, as of 1990, when the Constitution fully became in force, in comparison to precedent times, Chile has shown low and regular inflation levels. This phenomenon, in a great extent, is due to the incidence of Law.

KEYWORDS: Inflation - Central Bank - Monetarism - Constitution.
\end{abstract}

* Profesor de Derecho Económico de la Facultad de Derecho de la Pontificia Universidad Católica de Valparaíso. Dirección Postal: Facultad de Derecho, Pontificia Universidad Católica de Valparaíso, Chile. Correo electrónico: jose.guerrero@ucv.cl 


\section{El MONETARISMO Y SU INTRODUCCIÓN EN CHILE}

Bajo la vigencia de la Constitución Politica de la República de Chile ${ }^{1}$ de 1925, en Chile al igual que otros países, se ha discutido ideológica y políticamente el rol que debe tener el Estado en la economía, en un contexto mundial de coexistencia de dos modelos con pretensiones hegemónicas: el modelo de mercado y el modelo de planificación central. Así bajo la Constitución de 1925 se pueden identificar, particularmente desde 1932 en adelante, distintas concepciones o visiones político-económicas sobre el rol del Estado en la economía: Un Estado asistencial en la breve existencia de la denominada república socialista ${ }^{2}$, un Estado desarrollista y empresario, en los denominados gobiernos radicales de los presidentes Pedro Aguirre Cerda, Juan Antonio Ríos y Gabriel González Videla; un Estado con rol menos activo económicamente, en los gobiernos de los presidentes Carlos Ibáñez del Campo ${ }^{3}$ y Jorge Alessandri Rodríguez; un Estado subsidiario y redistribuidor propio de la economía social de mercado, bajo el gobierno del presidente Eduardo Frei Montalva y, finalmente, un Estado que intenta monopolizar ciertas áreas de la economía basado en una orientación político económica socialista durante el gobierno del presidente Salvador Allende ${ }^{4}$.

Para la implementación de estos diversas visiones político-económicas

${ }^{1}$ En adelante, la abreviación C.Pol. es referencia a la Constitución Política de la República de Chile de 1980. Cuando se cite la de 1925, se añadirá esta cifra.

${ }^{2}$ El programa económico de la denominada República Socialista de 1932 (4 de junio al 13 de septiembre de 1932), fue presentado por el Ministro de Hacienda, Alfredo Lagarrigue, quien lanzó un plan de política económica llamado de "las 40 medidas", conocido también como "Plan Lagarrigue", cuyas finalidades eran: "Alimentar al pueblo, vestir al pueblo, domiciliar al pueblo, entendiéndose por el pueblo al conjunto de los ciudadanos sin distinción de clase ni de partidos", Véase: Jobet, Julio César, El partido socialista de Chile ( $1^{\text {a }}$ Edición digital, Santiago, Prensa Latinoamericana, 2003), p.19 [disponible en www.salvador-allende.cl/Biblioteca/ps_jobet.pdf].

${ }^{3}$ El Gobierno del presidente Carlos Ibáñez del Campo (1952-1958) que se inició con el apoyo de fuerzas políticas de diversas tendencias, contrató a la misión KleinSacks para asesoría económica. Esta misión propuso establecer un programa de corte liberal y ortodoxo respecto de la política fiscal con control de remuneraciones, reducción del gasto público y limitación del crédito bancario. Véase: Valdés Soublette, Juan Gabriel, La escuela de Chicago, operación Chile (Buenos Aires, Grupo Editorial Zeta .A. ,1989), pp. 141-143.

${ }^{4}$ Períodos presidenciales mencionados: Pedro Aguirre Cerda (diciembre de 1938 a noviembre 1941); Juan Antonio Ríos (abril 1942 a junio 1946); Gabriel González Videla (noviembre 1946 a noviembre 1951); Carlos Ibáñez del Campo (noviembre 1952 a noviembre 1958); Jorge Alessandri Rodríguez (noviembre 1958 a noviembre 1964); Eduardo Frei Montalba (noviembre 1964 a noviembre 1970); y Salvador Allende Gossens (noviembre 1970 a septiembre 1973). 
sobre el rol del Estado en la economía no se hizo necesaria la modificación sustancial de las normas constitucionales vigentes desde 1925, salvo en la incorporación del concepto de función social de la propiedad en $1967^{5}$ y la denominada nacionalización del cobre en julio de $1971^{6}$.

Interrumpido el gobierno del presidente Allende por el pronunciamiento militar de septiembre de 1973, el Gobierno Militar, en sus inicios, debatió el carácter que las Fuerzas Armadas y de Orden darían a dicho gobierno: si sería un gobierno de restauración o bien un gobierno fundacional. Pilar Vergara estima que: "La pretensión fundacional se constituyó en el elemento definitorio de los desarrollos ideológicos posteriores, que es, por tanto el tópico generativo de toda la producción ideológica del régimen militar"7. Los primeros días del Régimen Militar se caracterizaron por un predominio de la opción restauradora; así lo expresan el Decreto-ley No 1 de la Junta de Gobierno, que justifica la constitución de ésta en el "patriótico compromiso de restaurar la chilenidad, la justicia y la institucionalidad quebrantadas"; y en los primeros bandos emitidos por la Junta de Gobierno. Sin embargo, rápidamente se impuso la opción de un proyecto fundacional en que se consideraba necesario no sólo restaurar sino que crear una nueva institucionalidad para el país.

En materia económica, de una primera etapa restauradora del liberalismo, el Gobierno Militar pasó a esa etapa fundacional desde el año 1975 y particularmente desde 1976, cuando se implementó el denominado "Plan de shock" bajo la conducción de economistas monetaristas o neoliberales formados en la Universidad de Chicago, conocidos coloquialmente en su época como los "Chicago Boys" .

Fueron estos economistas neoliberales y también llamados monetaristas ${ }^{10}$, 1967

${ }^{5}$ Reforma constitucional introducida por la Ley $N^{\circ} 16.615$, de 20 de enero de

${ }^{6}$ Reforma constitucional al artículo 10 No 10 C.Pol. de 1925, aprobada por Ley No 17.450, de 16 de julio de 1971

${ }^{7}$ Véase: Vergara, Pilar, Auge y caída del neoliberalismo en Chile (Santiago, FLACSO, 1985) p. 8.

${ }^{8}$ Guerrero Becar, José Luis, Regulación constitucional del orden económico. La experiencia chilena: Constitución Política de la República de 1980 (Memoria de licenciatura, 1991, Valparaíso, Universidad Católica de Valparaíso), pp.52-89.

${ }^{9}$ Valdés Soublette, Juan Gabriel, cit. (n. 3), p. 75.

${ }^{10}$ En un primer momento, la conducción económica del Gobierno Militar fue ejercida por la Armada de Chile, y se explica por los contactos que tenían muchos miembros de la oficialidad, en servicio activo y a veces en retiro, con el equipo económico que preparaba un proyecto alternativo en materia económica a aquel del gobierno del presidente Salvador Allende. Este plan económico alternativo se le conocía como el "ladrillo", y en él trabajaron varios economistas jóvenes, la mayoría post-graduados en 
quienes lograron desde 1976 en adelante controlar la inflación. En 1973, la inflación en Chile tuvo características de hiperinflación, pues alcanzó la cota, histórica para Chile, de 508,05\% anual. Para ejemplificar la magnitud y gravedad de la inflación de esa época, téngase presente que la inflación anual de Chile en el año 2006 alcanzó un 2,6\%, es decir, a sólo dos días de inflación de 1973; que el 2008, aún con una crisis mundial desatada, alcanzó un 7,1\% anual, esto es, a sólo cinco días de inflación de 1973; y, en fin, que en el año 2009 se registró una inflación negativa o deflación de -1.4\%.

A pesar de los intentos de controlar la inflación durante los primeros años del Gobierno Militar, el año 1975 aquélla alcanzó un no menos sorprendente $340 \%$. Frente a la ineficacia de las medidas estabilizadoras, el Gobierno Militar decidió entregar la conducción económica a los economistas chilenos formados en la Universidad de Chicago ${ }^{11}$, quienes, fieles a su pensamiento económico basado en el monetarismo o neoliberalismo, establecieron la premisa que estiman básica para la conducción macroeconómica: la economía debe privilegiar el control de la inflación por sobre otras variables macroeconómicas, como el pleno empleo, ya que los costos de la inflación, particularmente la pérdida de poder adquisitivo del dinero, afecta a los más pobres y genera desconfianza en el sistema económico. La teoría monetarista dice que la inflación es siempre un fenómeno monetario ${ }^{12}$ y que su principal causa es el déficit fiscal no respaldado en la producción del país; lo cual significa que la emisión del Banco Central de Chile (= BCCh. $)^{13}$ es sólo para financiar el déficit fiscal, sin que corresponda a una real capacidad productiva. Se trata, pues, de una emisión sin control ni sustento en la economía.

Los monetaristas establecieron como su objetivo principal evitar que el

la Universidad de Chicago, promocionados por la Sociedad de Fomento Fabril, organismo gremial que encargó la elaboración del proyecto al Centro de Estudios Socioeconómicos. Véase: Délano, Manuel - TraslaviÑa, Hugo, La herencia de los Chicago boys (Santiago, Ediciones del Ornitorrinco, 1989), p. 21; y Valdés Soublette, Juan Gabriel, cit. (n. 3), p.13.

${ }^{11}$ Para conocer los antecedentes históricos de la vinculación de muchos economistas chilenos con la Escuela de Economía de la Universidad de Chicago, EE.UU., véase: Rosende Ramírez, Francisco (editor), La Escuela de Chicago: Una mirada a 50 años del convenio Chicago/Universidad Católica: Ensayos en Honor de Arnold C. Harberger (Santiago, Ediciones Pontificia Universidad Católica de Chile, 2007); y VALdES Soublette, Juan Gabriel, La escuela de Chicago, operación Chile, cit. (n. 3), p. 13.

${ }^{12}$ Friedman, Milton, The New Palgrave Dictionary of Economics (1987), citado por Samuelson, Paul - Nordhaus, William, Economía (17 edición, Madrid, McGraw-Hill, 2002), p. 614: "La inflación es siempre y en todo lugar un fenómeno monetario en el sentido de que sólo es y puede ser producida por un aumento más rápido de la cantidad de dinero que de la producción".

${ }^{13}$ En adelante Banco Central de Chile por su abreviatura BCCh. 
BCCh. continuara financiando el déficit fiscal del país, basado en la antedicha premisa de que la principal fuente de la inflación es el déficit fiscal; y de que éste aumenta si es financiado por emisión del Banco Central sin respaldo de la economía. En efecto, la teoría clásica de control monetario de inflación, conocida como teoría cuantitativa del dinero ${ }^{14}$, ecuación de transacción o ecuación de Fischer, en honor a Irving Fischer, sostiene que, como la velocidad de circulación del dinero es estable, la emisión anual proyectada debe ser equivalente al nivel de producción proyectado; así que cuando se estime que la producción aumentará en un $10 \%$, atendido que es necesario disponer de dinero para realizar esas nuevas transacciones, la emisión de dinero debe aumentar en un $10 \%$, suponiendo constante la velocidad de circulación del dinero $^{15}$. Si aumenta la emisión en un porcentaje mayor al aumento de la producción, existirá inflación; y si en uno menor, deflación.

Los economistas monetaristas perfeccionaron la teoría cuantitativa del dinero. Particularmente Milton Friedman, desde $1956^{16}$, formuló una nueva

${ }^{14}$ Por todos, véase: MANKIw Gregory, Macroeconomia (6a edición, Barcelona, Bosch, 2009), pp.154-193

${ }^{15}$ La velocidad de circulación del dinero, para efectos de simplificar el entendimiento del lector, implica el número de veces que una unidad monetaria sirve para realizar una transacción. Por ejemplo, un billete emitido por el Banco Central de \$10.000 no servirá para realizar una única transacción por $\$ 10.000$, sino que la cuantificación de transacciones que ese billete permitirá dependerá de cuantas veces ese mismo billete se utilice. Así, si se necesita emitir dinero para realizar transacciones por $\$ 100.000$ y se conoce que la velocidad de circulación del dinero es 2 veces, si se emiten 10 billetes de 10.000 se producirá inflación porque como cada uno realiza 2 transacciones esos billetes aumentarán la masa monetaria en $\$ 200.000$. En el ejemplo bastaría emitir 5 billetes de $\$ 10.000$. El supuesto de la teoría clásica de los precios es que la velocidad del dinero es relativamente estable y predecible. Como dicho supuesto en la práctica no ha resultado efectivo, ya que han existido períodos de alta variación de la velocidad del dinero las autoridades monetarias desde la década del noventa han dejado de utilizarla como guía única de la política monetaria, y se ha ampliado las variable macroeconómicas a observar: producción, empleo, inflación.

${ }^{16}$ La teoría cuantitativa del dinero es una de las teorías más antiguas, pues sus orígenes se atribuyen a Martín de Azpilcueta, de la Escuela de Salamanca, en el siglo XVI; luego fue formulada en 1911 por Irving Fischer, en la denominada ecuación clásica de transacción o de Fischer (MV = PQ), mejorada por la Escuela de Cambridge (Marshall y Pigou), para luego ser desplazada por la visión keynesiana de demanda agregada, hasta su reformulación por Milton Friedman en la década del cincuenta, en orden a que el nivel de inflación no sólo depende de la oferta monetaria nominal (emisión o multiplicados monetario - tasa de encaje-), sino que del costo de oportunidad del dinero representado por la tasa de interés y los niveles de renta (ambos factores que determinan el nivel de demanda real de dinero). Véase: Friedman, Milton (editor) Studies in the Quantity Theory of Money, (1956, University Chicago Press); Samuelson, Paul - Nordhaus, William, cit. (n. 12); Mankiw, Gregory, Macroeconomía, cit. (n. 14). 
visión conocida comúnmente como teoría neocuantitativa del dinero y la inflación o teoría neoclásica del dinero. Al concepto de oferta monetaria y sus clásicas herramientas de control monetario de la emisión y el multiplicador monetario - tasa de encaje bancaria-, ya presentes en la teoría cuantitativa, esta nueva visión añadió el concepto de demanda real de dinero, que se controla por medio de dos herramientas de política económica: las tasas de interés y los ingresos o rentas. Así, y con la sola pretensión de ejemplificar el fenómeno económico al lector, una de las maneras de reducir la inflación bajo esta nueva mirada, es disminuir la masa monetaria en circulación; para ello es necesario que exista una baja demanda por saldos líquidos de dinero, es decir, una baja demanda de dinero para su función de medio de cambio; lo cual se puede lograr -además de reducir la emisión o subir el multiplicador monetario o tasa de encaje- aumentando el costo de oportunidad del dinero, de modo que disminuya la demanda de dinero en función de medio de cambio - para gastarlo- y paralelamente aumente la demanda de dinero como medio de acumulación de dinero - para ahorrarlo-. Si el dinero está en función ahorro, sale de circulación del mercado en un porcentaje, y disminuye la masa monetaria. Para incentivar el ahorro es necesario que la tasa de interés, que es el precio del dinero o costo de oportunidad del dinero que se determina por la oferta y demanda del mismo; debe ser atractivo para el ahorro y poco atractivo para el crédito, lo que se logra al subir la tasa de interés. Si se sube la tasa de interés de captacion, los agentes económicos, particularmente el público en general, tenderán a ahorrar ya que el dinero aumenta su costo de oportunidad y es más atractivo ahorrarlo que usarlo en consumo. Consecuentemente, si sube la tasa de captación, sube la tasa de colocación, y el financiamiento del gasto - corriente o de inversión- disminuye. De esta forma, ese dinero, al ser ahorrado, sale de circulación por un periodo de tiempo disminuyendo la masa monetaria. Si bien las empresas bancarias pondrán a su vez prestar ese dinero con lo cual volvería a circulación, lo hará en menor medida por dos razones: porque previamente debe aplicarse la tasa de encaje bancaria; y porque naturalmente deberán subir las tasas de interés de colocación, de modo que el banco tenga una ganancia o "spread" positivo ${ }^{17}$, desincentivando el crédito.

Así, cuando se requiera controlar la inflación, uniendo las herramientas de manejo de la oferta y de la demanda de dinero habrá de disminuirse la emisión, aumentar la tasa de encaje e incrementarse la tasa de interés; y todas esas medidas pueden adoptarse conjunta o alternativamente, según lo decida

17 "Spread" es un término económico utilizado para denotar el diferencial entre las tasas de captación (ahorro) y colocación (préstamos), que si es positivo constituye una de las principales fuentes de rentabilidad de un banco. 
la autoridad monetaria. Cabe destacar que estas tres herramientas se entregan normalmente a las autoridades monetarias representadas por los bancos centrales: ellos tienen el monopolio de la emisión, fijan las tasas de encaje y gozan de atribuciones para fijar tasas de interés en sus propios instrumentos $\mathrm{y}$ de esta forma influyen en las tasas de interés del mercado en general ${ }^{18}$.

Por último, el manejo de los ingresos es una herramienta de política económica que normalmente no dependerá de la autoridad monetaria, ya que un Banco Central no puede directamente bajar los ingresos de la población para disminuir los saldos líquidos de dinero en su poder, por lo que, si bien es una herramientas de política económica, su manejo excede a las autoridades monetarias.

En Chile, al año 1975, la normativa que regulaba al BCCh. estaba lejos de seguir la reformulación de la teoría cuantitativa del dinero que incorpora un rol central de la autoridad monetaria en el manejo de la inflación y especialmente una prohibición conceptual a que el emisor, BCCh. financiara la deuda del Estado ya que ello implicaba emitir dinero sin respaldo productivo y producía déficit fiscal, el cual, a su vez, se convierte en una de las principales fuentes de la inflación. Contrario a estos conceptos monetaristas, el BCCh., desde su ley orgánica de 1953 , tenía como objetivo adicional a la estabilidad monetaria, el de contribuir al desarrollo del país, financiando deuda pública, lo que es coherente con las teorías keynesianas predominantes luego de la gran depresión de 1929. Ahora bien, para los neoliberales, particularmente desde fines de la década del cincuenta, tal premisa es contradictoria con el objetivo de la estabilidad monetaria.

Si se revisa la historia normativa del BCCh., en cuanto organismo de control monetario, se ve que, desde su primera ley orgánica, el Decreto-ley No 486, de $1925^{19}$, tuvo como objetivo la estabilidad monetaria -o no inflación ni deflación-. Sin embargo, entre 1925 y 1953 -de este último año es la segunda ley orgánica-, la inflación en Chile fue una constante, debiéndose tener presente que en dicho período el país debió enfrentar las repercusiones económica del término del período del salitre, la gran depresión mundial de

${ }^{18} \mathrm{Si}$ el Banco Central sube la tasa de instancia monetaria, los bancos que negocian con él subirán, a su vez, las tasas que ofrecen a otros banco o a sus clientes.

${ }^{19}$ Sobre el rol del BCCh. conforme a su primera ley orgánica de 1925, cabe tener presente que previo a su creación cada banco privado emitía circulante respaldando su emisión en su reserva de oro. Con la creación del BCCh., se monopolizó la emisión de circulante, para lo cual el BCCh. se constituyó en sociedad anónima, siendo uno de sus accionistas los bancos privados existentes en Chile que pagaron sus acciones con dación en pago de sus reservas en oro. No se estableció una prohibición al BCCh. de operar con el propio Estado, por lo que se convirtió en una fuente de crédito permanente para éste. A dicho efecto el banco emite circulante incrementándose la masa monetaria y con ello la inflación al menos de corto plazo. 
1929 y la Segunda Guerra Mundial. Es en este período histórico en que el rol del Estado de Chile como actor económico activo fue indiscutido y, en general, no se objetaba su función desarrollista y empresarial ${ }^{20}$.

En 1953 se promulgó la segunda ley orgánica del Banco Central, el Decreto con fuerza de ley $\mathrm{N}^{\circ} 106$, que confirmó el rol monetario del BCCh., pero incorporó explícitamente un rol de apoyo al Estado. Se declaró que: "El Banco Central de Chile tendrá por objeto propender al desarrollo ordenado y progresivo de la economía nacional y crediticia que, procurando evitar tendencias inflacionistas o depresivas, permita el mayor aprovechamiento de los recursos productivos delpais". ${ }^{21}$ De lo anterior se desprende que, en esta etapa, sin dejar de lado sus funciones propiamente monetarias, el BCCh. pasó a desempeñar un rol más activo en el desarrollo de la economía nacional, priorizando el pleno empleo de los recursos productivos. En este sentido, el nuevo texto legal facultó al Banco Central para conceder créditos al Fisco y a organismos estatales. No obstante el carácter facultativo de dichas operaciones, se obligó al instituto emisor a descontar letras de cambio giradas por la Caja Autónoma de Amortización de la Deuda Pública a cargo del Tesorero General de la República, con el objeto de regularizar los ingresos de la caja fiscal ${ }^{22}$.

La tercera ley orgánica del $\mathrm{BCCh}$. fue el Decreto con fuerza de ley $\mathrm{N}^{\circ}$ 250, de 30 de marzo de 1960, que conservó el objetivo antes expresado, por lo que el BCCh. continuó obligado a otorgar préstamos al Estado a efectos de contribuir a su rol desarrollista y empresario.

Este escenario mantuvo al BCCh. en un constante desfinanciamiento; paralelamente, el déficit fiscal del Estado comenzó a aumentar al financiarse la deuda fiscal con créditos otorgados al Fisco por el BCCh. Por consiguiente, éste otorgaba préstamos, para lo cual emitía dinero, sin que luego recibiera el pago oportuno de parte del Fisco, con lo cual debía constantemente emitir sin una contrapartida productiva, vulnerando las teorías monetaristas básicas de

\footnotetext{
${ }^{20}$ Muñoz Gomá, Oscar, Chile y su industrialización. Pasado, crisis y opciones (Santiago, Cieplan, 1986), p. 208.

${ }^{21}$ Artículo 2 DFL. No 106 de 1953 , que contiene la Ley orgánica del Banco Central.

${ }^{22}$ Artículo 39 DFL No 106 de 1953: "El Banco Central de Chile, con arreglo a las finalidades establecidas en el articulo 2 del presente decreto con fuerza de ley, y en ejercicio de su facultad emisora, podrá efectuar las siguientes operaciones: a) Conceder créditos al Fisco, Instituciones semifiscales, de Administración Autónomas y Municipalidades, en las condiciones establecidas en leyes especiales. No obstante el carácter facultativo de las operaciones indicadas en el inciso anterior, el Banco deberá descontar letras de cambio giradas por la Caja Autónoma de Amortización de la Deuda Pública, a cargo del Tesorero General de la República, por el plazo y condiciones y hasta por el monto señalados en la ley $N^{\circ} 7.200$, de 21 de julio de 1942, con el objeto de regularizar los ingresos de la Caja Fiscal".
} 
la estabilidad monetaria, que era un objetivo que también se le encomendaba legalmente a dicho Banco.

La visión teórica del déficit fiscal como gran causante de procesos inflacionarios es fácil advertirla al revisar estadísticas del caso chileno. En esa perspectiva, Juan Andrés Fontaine sostiene que la causa inmediata de la tasa de inflación anual promedio de un 30\% entre 1940 y 1970 fue la excesiva expansión monetaria para financiar el presupuesto fiscal ${ }^{23}$.

Esta situación se incrementó durante el gobierno del Presidente Allende, en que el déficit fiscal, de constituir cerca de un 6\% del Producto Interno Bruto en el año 1970, pasó a un 30,9\% en 1973, motivado por un aumento de los gastos corrientes del Fisco, particularmente en remuneraciones y transferencias al sector público, que aumentaron en un $72 \%$, frente a un descenso de los ingresos corrientes a un $29,1 \%$, produciéndose el déficit ya señalado ${ }^{24}$. A su turno, la inflación pasó de un 35\% anual en 1970 a un $508,05 \%$ en $1973^{25}$.

El Gobierno Militar, ante la imposibilidad de controlar una hiperinflación a corto plazo, lo que se manifestó con un índice de inflación de $341 \%$ en 1975, decidió intentar la implementación del proyecto de los economistas que sustentaban la teoría neoclásica de control de la inflación. De hecho, ya en el año 1976 lograron que la inflación sólo fuese de un 174\%; y que en 1981 se redujera a un sorprendente $10 \%$ anual.

En los años posteriores, aún durante y después de la crisis de 1982, la inflación nunca tuvo nuevamente características de hiperinflación ${ }^{26}$. Su

${ }^{23}$ Fontaine, Juan Andrés, Transición económica y politica en Chile: 1970-1990, en Estudios Públicos, 50 (Otoño de 1993), p. 239.

${ }^{24}$ Bitar Chacra, Sergio, Chile 1970-1973, Asumir la historia para construir el futuro (Santiago, Pehuen, 1995), p. 97.

${ }^{25}$ Como datos adicionales, en el año 1975 - previo a la conducción monetarista de la economía chilena- la inflación anual fue de 341\%; y en el año 1980, año de aprobación de la nueva Constitución, y comienzo, por ende, de la prohibición de financiamiento de la deuda fiscal por el BCCh., la inflación alcanzó un 31\%

${ }^{26}$ Fontaine Juan Andrés, Transición económica y politica en Chile: 1970-1990, cit. (n 23), señala sobre este período histórico: "Debido a su entrenamiento profesional, los militares tenían una visión nacionalista de la economía. Las políticas proteccionistas les parecían más propicias para la seguridad nacional que las propuestas de libre comercio. De modo similar, el estricto control gubernamental de las actividades económicas "estratégicas" parecía como la extensión natural, a la esfera económica, de su inclinación nacionalista. La retórica neoliberal de los economistas de Chicago provocaba no poca desconfianza. Y tal actitud no sólo estaba presente entre los militares sino también entre la mayoría de los partidarios civiles del Gobierno. El golpe había sido apoyado por los democratacristianos y los conservadores. Aunque formalmente disueltos, sus líderes tuvieron al comienzo gran influencia entre los militares. Por tradición y doctrina éstos estaban a favor del estatismo. Querían recrear el Estado redistributivo anterior a 1973. 
promedio anual entre 1982 y 1989 fue de un $20.77 \%$; entre 1990 y 1999 , de un 10,76\%; y entre el año 2000 y 2008, de un 3,83\%. Cabe considerar que en las últimas dos décadas se han vivido dos importantes crisis económicas: la crisis asiática 1997 y 1999, en que el promedio anual de inflación fue de un 4.3\%; y la crisis financiera iniciada en el año 2008.

\section{LAS HERRAMIENTAS LEGALES DE LA POLÍTICA MONETARIA}

\section{De la biperinflación a la inflación moderada.}

Desde 1976 en adelante no han existido períodos que pudiesen estimarse de alta inflación o hiperinflación. El período más alto de inflación anual se experimentó entre 1989 y 1990, con un 21 y 27\% anual respectivamente. Salvo esos años que corresponden a la coyuntura histórica particular, de transición a la democracia, con aumento del gasto público e inicio de vigencia de la Ley. No 18.840: Orgánica constitucional del Banco Central de Chile, de 10 de octubre de $1989^{27}$, con la consecuente designación de su primer Consejo propiamente autónomo ${ }^{28}$, durante los restantes años los índices de inflación

Al final triunfaron los economistas de Chicago gracias a su contundente capacidad técnica -basada en la lógica aplastante de la teoría económica- y también en buena medida debido a factores exógenos. Una severa crisis de la balanza de pagos a principios de 1975 -consecuencia del alza de los precios internacionales del petróleo en 1973 y de la caída de los precios de los bienes en 1974- cambió el curso de los hechos. En una reunión histórica realizada en Viña del Mar, el general Pinochet y sus colaboradores más cercanos se abocaron a discutir dos planes de estabilización alternativos. El primero, prudentemente gradual y basado en una creciente ayuda financiera internacional. El otro, un shock fiscal y monetario destinado a restaurar rápidamente la viabilidad de la balanza de pagos y a detener la espiral inflacionaria. El general -nada de amigo de las opciones tibias- escogió el tratamiento de shock. Intuía que la situación era extremadamente delicada y confiaba en la capacidad profesional de los tecnócratas que apoyaban la terapia de shock. En abril de 1975, Jorge Cauas, Ministro de Hacienda, y Sergio de Castro, Ministro de Economía, con la ayuda de un amplio equipo de economistas jóvenes, comenzaron la construcción del modelo económico chileno".

${ }^{27}$ En adelante LOCBCCh.

${ }^{28}$ La designación del primer Consejo del BCCh. bajo la vigencia de la LOCBCCh. fue objeto de un consenso entre el Gobierno Militar y la oposición política al año 1989, atendido que el plazo para su nombramiento vencía una semana antes de las elecciones de Presidente y parlamentarios. Bianchi, Andrés, La autonomía del Banco Central de Chile: Origen y legitimación, en Revista Economia Chilena, 12 (2009) 3, p.11 [disponible en www.bcentral.cl/estudios]: "A su vez, en el seno de la Concertación era necesario persuadir a sus principales líderes de que la negociación era una opción preferible a la confrontación. Pero, para ello, era preciso no solo obtener una participación cuantitativa adecuada en el Consejo, sino también lograr que el Gobierno aceptara en él a personas que, en conjunto, representaran a los principales partidos integrantes de la coalición opositora. No obstante estas dificultades y gracias a la tenacidad y visión 
han sido moderados para el promedio histórico de Chile y desde el año 1990 en adelante ofrecen una tendencia clara a la baja de los niveles de inflación.

Sólo a efecto de comparación, observemos la inflación promedio en la Comunidad Andina de Naciones, que en el año 1994 fue de 30,4\% ${ }^{29}$; y en Sudamérica, donde alcanzó de un 467.2\%, si bien este promedio estuvo influido por la hiperinflación de Brasil (916,5\% ) y Venezuela (70,4\%), ese año Chile registró un $8.9 \%$. En el año 2004, Sudamérica registro un promedio de inflación de 7,2\% y Chile 2,4\%

Ante la evidencia estadística de una menor inflación promedio en Chile que en el resto de Sudamérica, particularmente desde el año 1990 en adelante, cabe preguntarse qué mecanismos aplica Chile para el manejo de la inflación, y si obedecen al diseño de un mero manejo económico o responden a un diseño institucional.

Si se revisa la teoría económica de la segunda mitad del siglo XX, particularmente entre las décadas del ' 50 al ' 90 , se verifica que, en realidad, no ha habido innovaciones fundamentales en la teoría económica monetaria. La ecuación de transacción y las teorías monetarias datan de principios del siglo XX, y ya Milton Friedman escribía sobre la teoría neocuantitativa de la inflación y el dinero, con la tasa de interés como principal instrumento de control monetario, en la década de los ' 50.

Si la teoría era la misma, entonces, épor qué esta vez, desde el año 1976, el BCCh. pudo acercarse al objetivo de estabilidad monetaria?

del Ministro Cáceres y al realismo de Alejandro Foxley -quien, como más seguro candidato al cargo de Ministro de Hacienda, comprendió las ventajas relativas que para el futuro gobierno representaba una solución de compromiso-, se pudo avanzar desde una posición inicial, en que el Gobierno proponía que el Consejo estuviese integrado por cuatro miembros vinculados al régimen militar y un independiente, a un acuerdo en que aquel incluiría dos miembros ligados al Gobierno, dos pertenecientes a la Concertación y uno de carácter independiente aceptable para ambas partes. Este compromiso para conformar un Consejo de carácter pluralista se dio a conocer el 4 de diciembre. Por el lado del Gobierno, sus integrantes fueron Enrique Seguel -General del Ejército, que había presidido el Banco Central entre 1985 y 1988 y que en 1989 había sido nombrado Ministro de Hacienda- y Alfonso Serrano, economista que ocupaba la vicepresidencia del Banco desde 1985. Por la Concertación fueron nominados Roberto Zahler, experto monetario de la CEPAL, de filiación demócrata-cristiana, y Juan Eduardo Herrera, economista del Partido por la Democracia, quien a la sazón se desempeñaba como alto ejecutivo de una empresa minera privada. El autor del presente artículo [Andrés Bianchi], en ese momento Secretario Ejecutivo Adjunto de la Cepal, fue elegido presidente del Banco por consenso del Gobierno y la Concertación por un período de dos años".

${ }^{29}$ Principales indicadores de la Comunidad Andina de Naciones, 1994-2004. Documento estadístico Secretaría General 123-2005 [disponible en http://www.comunidadandina.org/estadisticas/SGde123.pdf]. 
En mi opinión, una gran influencia en el éxito inicial del modelo monetarista en Chile en cuanto al control de la inflación, la tuvo una ciencia algo olvidada desde el siglo XIX por los economistas matemáticos: el Derecho. En efecto, los monetaristas, a pesar de su estricto apego al modelo teórico, especialmente en sus primeros años, advirtieron que la legislación es indispensable para establecer un orden económico que les permitiera sustentar sus teorías, y utilizaron como instrumento para la materialización de su modelo, el diseño institucional y normativo.

No es casualidad que la denominada Escuela de Chicago no sólo ha sido impulsora del Neoliberalismo y principalmente del monetarismo, que implica el control de la economía a partir del control de la moneda y la inflación, sino que también se han preocupado del Derecho, bajo la forma que hoy llamamos análisis económico del Derecho. Sus orígenes no están en Chicago, sino en las investigaciones de Ronald Coase en el London School of Economics en 1937; pero su desarrollo posterior, con el propio Coase como Richard Posner, se realizó en la Universidad de Chicago ${ }^{30}$. A partir de este nuevo enfoque, de vincular el Derecho con la Economía, queda en evidencia que las condiciones para que un país genere riquezas son tres: $i$ ) estabilidad monetaria; $i$ ) equilibrio fiscal; y iii) un orden jurídico económico en un Estado de Derecho. Estos principios también son compartidos por la Escuela Austriaca de Economía ${ }^{31}$.

${ }^{30}$ Véase: García, José Francisco - Lima, Víctor, Derecho y Economía: Aire no te vendas, en Rosende, Francisco (editor) La Escuela de Chicago: Una mirada histórica a 50 años del convenio Chicago-Universidad Católica (Santiago, Ediciones Universidad Católica de Chile, 2007), pp. 262-291

${ }^{31}$ Sobre las similitudes entre la Escuela de Chicago y Escuela Austriaca, escribe EBELING, Richard, El Estado y la planificación central de la moneda. Los economistas austriacos y de Chicago opinan sobre la moneda, la inflación y la gran depresión (traducción castellana de Eneas A. Biglione y Germán Messina) [disponible en http://www.atlas. org.ar/economia/ebeling_2.asp Ebeling]: "En el período posterior a la segunda guerra mundial, las dos escuelas líderes en el pensamiento de libre mercado han sido la Escuela Austriaca, encabezada por Ludwig Von Mises y Friedrich Von Hayek; y la Escuela de Chicago, encabezada por Milton Friedman y George Stigler. Juntas, han realizado un análisis de gran rigurosidad y lucidez, criticando los peligros y errores de las políticas socialistas, keynesianas e intervencionistas. Pese a las diferencias entre sus respectivos métodos de análisis, ambos grupos han alcanzado una conclusión similar: solo una economía de libre mercado puede asegurar Libertad y prosperidad. Ambas escuelas rechazan el argumento keynesiano acerca de la inestabilidad de la economía de mercado y su tendencia a generar períodos extensos de desempleo y recursos ociosos. Ambas sostienen que cuando se suceden períodos inflacionarios o de depresión económica, ocurren como resultado de la intervención del Estado, que tiende a reducir la flexibilidad del mercado para hacer frente a los cambios circunstanciales. Y finalmente, ambas escuelas de pensamiento intuyeron que las políticas monetarias y fiscales (particularmente del 
El uso del Derecho como instrumento para implementar modelos económicos no se acaba en los monetaristas; también se maximiza en el modelo económico socialista; un ejemplo claro de ello es la Constitución de la República de Cuba, que es una de las constituciones en actual vigencia más explícitas en materia de definición del sistema y del modelo económico al cual debe adscribirse la economía del país en que rige; en este caso, se trata de la opción constitucional por una economía de planificación central ${ }^{32}$.

Los monetaristas chilenos advirtiendo que no bastaba con un mero manejo de la emisión y de la tasa de interés desde el BCCh. para poder detener la inflación, y decidieron identificar la que se estima en teoría monetarista la principal causa de la inflación: el déficit fiscal, y atacarla. Advirtieron fácilmente que contribuía en gran medida a dicho déficit el hecho que el BCCh. actuara como prestamista del Estado, merced a la emisión de moneda.

Fue por lo anterior que en 1975 se emitió el Decreto-ley No 1.078, cuarta ley orgánica del Banco Central de Chile, que establece que éste sólo puede otorgar prestamos al Fisco mediante leyes especiales. En el año 1979, ya más categóricamente, el Decreto-ley No 3001 modificó el artículo 20 del Decretoley N 1.078 de 1975, disponiendo que: "Es atribución del Banco Central actuar como Agente Fiscal en la contratación de créditos externos e internos y en aquellas operaciones que le encomienda el Fisco, que sean compatibles con las finalidades del Banco. En ningún caso el Banco Central podrá adquirir para sí pagarés descontables de la Tesorería General de la República u otros documentos de créditos emitidos directamente por el Fisco, como tampoco otorgar créditos directos a las entidades y empresas, de los sectores público y privado, excepto a las instituciones financieras, sean públicas o privadas" ${ }^{33}$. Es claro que esta norma enfrenta el control de la inflación a través de la eliminación de su principal causa: la deuda fiscal financiada con emisión del BCCh.

tipo keynesiano) provocarían menor estabilidad y no más. Pero los economistas de la escuela Austriaca y los de Chicago, han diferido en un número importante de puntos en el campo de la historia, la teoría y la política monetaria. Una diferencia fundamental, son las diferentes interpretaciones acerca de los orígenes y soluciones a la Gran Depresión del 30. Las distintas interpretaciones sobre dicho período surgen a partir de sus diferentes concepciones de la influencia del dinero en la economía. Y esas disidencias nacen a partir de los distintos criterios utilizados para estudiar el proceso económico".

${ }^{32}$ A vía de ejemplo, la Constitución de la República de Cuba define, entre otros, como rol del Estado: "Dirigir planificadamente la economía nacional" artículo 9 letra a). Luego el artículo 14 dispone: En la República de Cuba rige el sistema de economía basado en la propiedad socialista de todo el pueblo sobre los medios fundamentales de producción y en la supresión de la explotación del hombre por el hombre. También rige el principio de distribución socialista "de cada cual según su capacidad, a cada cual según su trabajo. La ley establece las regulaciones que garantizan el efectivo cumplimiento de este principio"..

${ }^{33}$ Artículo 27 DFL. 3001, Diario Oficial de 27 de diciembre de 1979. 
Un año después, en 1980, este principio fue elevado a rango constitucional, pues la Constitución de ese año prevé un capítulo especial para el BCCh. -el $12^{\circ}$ - en cuyo artículo $109^{34}$ quedó establecida la prohibición de otorgar garantías o financiamiento al Estado y a sus organismos o empresas. Antes, el artículo 108 C.Pol. otorga autonomía al BCCh. y le reconoce un carácter técnico que, en mi opinión, debe interpretarse en un sentido restrictivo, en cuanto distinto a un órgano político, lo que se reafirma, luego, en la LOCBCCh., cuando su artículo 1 dispone: "El Banco Central de Chile es un organismo autónomo, de rango constitucional, de carácter técnico, con personalidad jurídica, patrimonio propio y duración indefinida [...]”.

\section{Reconocimiento constitucional del Banco Central de Chile y estableci-} miento de autonomía.

El reconocimiento constitucional y la autonomía otorgada al BCCh. en la Constitución es una innovación en el Derecho constitucional chileno. Según Arturo Irarrázaval: "La razón de ser de esta innovación guarda relación directa con la experiencia histérica en Chile que hizo que el ejecutivo, por intromisión muchas veces del Congreso, apelase al endeudamiento con el Banco Central para efectos de obtener recursos no presupuestados. Este endeudamiento significo en parte que el país llegase a tener niveles de inflación en 1972 y 1973 nunca antes vistos en la historia económica chilena y pocas veces visto en otros países"35.

Luis Felipe Céspedes y Rodrigo Valdés señalan que: "Otorgar independencia al Banco Central ha sido una forma de establecer un compromiso con la estabilidad de precios y a la vez permitir que éste implemente una política monetaria que contribuya a suavizar el ciclo económico. En la medida en que el banco central sea independiente de las necesidades de financiamiento del gobierno, se eliminará el sesgo inflacionario atribuible al financiamiento de un déficit público recurrente" ${ }^{36}$.

\footnotetext{
${ }^{34}$ Artículo 109 C.Pol.: “El Banco Central sólo podrá efectuar operaciones con instituciones financieras, sean públicas o privadas. De manera alguna podrá otorgar a ellas su garantia, ni adquirir documentos emitidos por el Estado, sus organismos o empresas. Ningún gasto público o préstamo podrá financiarse con créditos directos o indirectos del Banco Central. Con todo, en caso de guerra exterior o de peligro de ella, que calificará el Consejo de Seguridad Nacional, el Banco Central podrá obtener, otorgar o financiar créditos al Estado y entidades públicas o privadas. El Banco Central no podrá adoptar ningún acuerdo que signifique de una manera directa o indirecta establecer normas o requisitos diferentes 0 discriminatorios en relación a personas, instituciones o entidades que realicen operaciones de la misma naturaleza".

${ }^{35}$ Irarrázaval, Arturo, Principios económicos de la Constitución de 1980, en Revista Chilena de Derecho, 14 (1987), p.111.

${ }^{36}$ CÉspedes, Luis Felipe - Valdés, Rodrigo, Autonomía de Bancos Centrales: La
} 
La autonomía del BCCh. debe entenderse en cuanto independencia respecto del Gobierno y otros poderes del Estado, para la adopción de sus medidas económicas. Esta autonomía, consagrada constitucionalmente, parece verse disminuida en el artículo $6^{\circ}$ inciso $2^{\circ}$ de la LOCBCCh., cuando dispone: "El Consejo, al adoptar sus acuerdos, deberá tener presente la orientación general de la politica económica del Gobierno". Sin embargo, estimo que esa norma reafirma la autonomía del banco, pues ella dispone que el Consejo sólo deba “tener presente” la política económica del Gobierno, no que esté obligado a aplicarla u obsequiarla.

A efectos de que el BCCh. pueda realizar su labor técnicamente, es indispensable la autonomía referida. Tanto la Constitución como la LOCBCCh. establecen una seria de resguardos tendientes a preservar el carácter técnico y autónomo del órgano. Manifestaciones de ello son, por ejemplo, el nombramiento de consejeros que requieren de la intervención del Presidente de la República y el Senado; la duración de 10 años en los cargos; la sucesión por parcialidades cada dos años, lo que impide que las mismas autoridades políticas puedan designar a todos los consejeros partiendo de la base que no existe en Chile reelección presidencial; las causales de cesación en el cargo expresamente establecidas y que requieren de la decisión de más de un órgano político; la fijación de las más altas remuneraciones para el sector financiero privado; la prohibición constitucional de otorgar garantía o financiamiento al Estado, organismos o empresas, personalidad y patrimonio propio; que el Banco ejercita sus funciones y atribuciones con ceñimiento exclusivo a su ley orgánica, sin serle aplicable las disposiciones generales o especiales dictadas o que se dicten para el sector público; que no se le apliquen las disposiciones de la Ley No 18.575, sobre Bases generales de la administración del Estado; que sus trabajadores se rijan por su propio reglamento y por el Código del Trabajo. Todo lo cual denota el fin de hacer real la autonomía y de mantener el carácter técnico del BCCh., para que no quede sujeto a los vaivenes de la contingencia política.

La pretensión de dotar de autonomía al BCCh. se aprecia en las actas de la Comisión de Estudios de la Nueva Constitución. Destaca la intervención del fiscal del BCCh. de la época, Roberto Guerrero del Río, particularmente por la similitud de sus palabras ante la Comisión de Estudios con el texto definitivo de la Constitución. Dijo en la ocasión: "El señor Guerrero (Fiscal del Banco Central) expresa que desarrollará los principales principios que, a juicio de los personeros del área económica, es importante establecer en la Carta Fundamental [...]. Hacepresente que otro punto, sobre el cual es importante considerar

experiencia chilena, en Documentos de Trabajo del Banco Central de Chile, 358 (2006), pp. 4-5. 
algunos aspectos, es el relativo al gasto público. En esta materia, destaca que el principio fundamental es que el Fisco obtiene sus recursos de impuestos, aranceles o del endeudamiento que contrae el Estado, todo lo cual debe ser establecido por ley. Puntualiza que el endeudamiento sólo tiene que ser a mediano o largo plazo, para fines especificos, y, por vía de ejemplo, cita el caso de un endeudamiento a diez años para construir el camino de Chiloé Continental. Añade que además debe existir una probibición en materia de endeudamiento, en cuanto a que el Fisco no puede endeudarse con el Banco Central ni con ninguna entidad del Estado porque se estaría creando un gasto o generando una emisión; es decir, quedaría autorizado para endeudarse en el mercado de capitales emitiendo papeles a cinco o diez años plazo, o en el mercado externo a través de préstamos con las entidades financieras del exterior. Indica que otro punto se refiere a la independencia de la autoridad monetaria y cambiaria. Considera que en el texto constitucional debiera existir un reconocimiento, similar al de la Contraloría, respecto del Banco Central, cuya enunciación fundamental de funciones debiera estar fijada en la regulación de la política monetaria y cambiaria. Además piensa que este banco debiera ser un organismo independiente, carácter que, a sujuicio, puede concretarse a través de los nombramientos ( $P$. de la $R$. con acuerdo del Senado, inamovibles, salvo notable abandono de sus funciones, renovación cada 8 ó 10 años y por parcialidades para garantizar la continuidad en el manejo de una politica económica independiente. Cree indispensableprohibir que el Banco Central otorgue créditos directa o indirectamente al Estado o a los organismos que dependen del Estado, porque ello puede ser fuente de emisión contraria a una politica monetaria sana" 37

Luego de la exposición del fiscal del BCCh., el presidente de la Comisión de Estudios de la Nueva Constitución, Enrique Ortúzar, expresó: “[...] interesaba precisamente a la Comisión tener ideas más precisas sobre la independencia de la autoridad monetaria y cambiaria, porque se ha concordado en la necesidad de dejarla al margen de cualquiera intervención política o demagógica, como ocurrió en el pasado. Le parece muy adecuada la idea de que el Presidente de la República lleve a cabo la designación, de las autoridades máximas de este organismo, con acuerdo del Senado y de que el plazo de duración sea de ocho o de diez años, siendo inamovibles, a menos que incurran en alguna causal de acusación, de aquellas que dan origen al juicio politico"38.

Es importante comprobar que el artículo 109 incisos $1^{\circ}$ y $2^{\circ} \mathrm{C}$.Pol. recoge casi exactamente estos planteamientos: "El Banco Central sólopodrá efectuar operaciones con instituciones financieras, sean públicas o privadas. De manera

${ }^{37}$ Actas Oficiales de la Comisión de Estudio de la Nueva Constitución Politica de la República, sesión 384a a miércoles 14 de junio de 1978, p. 2.818.

${ }^{38}$ Actas oficiales de la nueva constitución política de la República (n. 37) p. 2819. 
alguna podrá otorgar a ellas su garantía, ni adquirir documentos emitidos por el Estado, sus organismos o empresas. Ningún gasto público o préstamo podrá financiarse con créditos directos o indirectos del Banco Central" ${ }^{\prime 3}$.

Igualmente, las normas de contenido económico del artículo 64 C.Pol., que designa las materias de ley, recogen de manera casi idéntica, los planteamientos expuestos como principales principios que, a juicio de los personeros del área económica del Gobierno Militar era importante establecer en la Carta Fundamental.

\section{El carácter técnico del Banco Central de Chile.}

El artículo 108 C.Pol. define al BCCh. como un organismo autónomo, con patrimonio propio, de carácter técnico.

La autonomía técnica del banco se refiere esencialmente a la capacidad de establecer sus propios acuerdos y adoptar sus propias decisiones en el ejercicio de sus atribuciones ${ }^{40}$.

Según el Diccionario de la Real Academia, las voz “a u to no mía” implica, en las acepciones aplicables al caso: "1. Potestad que dentro de un Estado tienen municipios, provincias, regiones u otras entidades, para regirse mediante normas y órganos de gobierno propios, 2. Condición de quien, para ciertas cosas, no depende de nadie". A su turno, el vocablo "técnico" conforme al mismo diccionario, corresponde a persona que posee los conocimientos especiales de una ciencia o arte ${ }^{41}$

El carácter técnico del BCCh. pareciera implicar que dicha entidad debe actuar conforme a las reglas de la técnica del área o ciencia que desarrolla. En este caso, la ciencia no ha de ser otra que la Economía, y un Banco Central tiene como rol esencial el monopolio de la emisión de dinero circulante, vale decir, de proveer de éste a la economía para poder realizar transacciones. A efectos que el dinero cumpla esta última función, debe contar con un

${ }^{39}$ Sobre autonomía del BCCh., que no es objeto central de este trabajo, véanse, entre otros: BIANCHI LARRE, Andrés, La autonomía del Banco Central de Chile: origen y legitimación, cit. (n. 28); De Gregorio, José. A veinte años de la Autonomía del Banco Central de Chile, en Economia Chilena, 12 (2009) 3 [disponible en www.bcentral.cl]; Ferrada, Juan Carlos, La autonomía del Banco Central: Breve excurso de su contenido jurídico, en Gaceta Jurídica (1997) 2; FerRADA, Juan Carlos, La autonomía del Banco Central: Reflexiones acerca de este modelo institucional de gestión de la politica monetaria, en Revista Chilena de Derecho (2003), pp. 151-166, Piñera ECHEniQue, Sebastián, Autonomía del Banco Central, en Revista de Derecho Público, 62 (2000), pp. 80-87, Rosende, Francisco, La autonomía del Banco Central de Chile: Una evaluación preliminar, en Cuadernos de Economía, 91 (1993), pp. 293-326.

${ }^{40}$ Véase: en http://www.bcentral.cl/acerca/funciones/03.htm

${ }^{41}$ Véase: Real Academia Española, Diccionario de la Lengua Española (21 ${ }^{\circ}$ edición, Madrid, 1992), I, p. 234 [también disponible en www.rae.es]. 
poder adquisitivo; y superado el patrón oro, el valor intrínseco del dinero en las economías modernas viene dado por el respaldo que el órgano emisor entregue a ese dinero para que pueda cumplir su función de intercambio y pago de obligaciones. Aquél, pues, debe perseguir que el dinero que emita tenga poder adquisitivo; de otro modo, no será utilizado por los agentes económicos y continuar su emisión pierde sentido ${ }^{42}$.

El poder adquisitivo del dinero varía por alteraciones en los sistemas de precios, ya sea que estos tengan un alza sostenida, que impliquen que el dinero aumenta más que la producción, perdiendo su poder adquisitivo; ya sea porque los precios presentan bajas sostenidas, que si bien le hacen aumentar el poder adquisitivo, impide que pueda cumplir su función de determinación de precios en bienes de bajo valor.

Lo anterior se puede ejemplificar de la siguiente forma: si la economía produce 10 bienes, y el Banco Central provee 1.000 unidades monetarias para esas transacciones, el precio de cada unidad será de $\$ 100$. Si aumentan las unidades monetarias a 2.000 sin aumentar la producción, cada bien tendrá un precio de $\$ 200$. En el primer caso, cada unidad monetaria tenía poder adquisitivo de 0.01 bienes, y en el segundo caso, 0,005 bienes, es decir, la mitad. Hay una perdida de un $100 \%$ de poder adquisitivo y en eso consiste la inflación.

En sentido contrario, si bajan los precios sostenidamente, el dinero tampoco cumple su función, porque no permitirían valorizar los bienes; por ejemplo, si un televisor de alta tecnología tiene un valor de 100 unidades monetarias, ¿cuánto costará un dulce? quizás 0,000001 unidad monetaria, y el sistema de circulante, esto es, los billetes y monedas, no puede operar en esa cifras fraccionarias, de modo de dejar de cumplir su función.

Entonces, si el Banco Central es el monopolista de la emisión de dinero, y el objetivo de esa función es proveer de medios de pago a la economía, su preocupación debe ser darle poder adquisitivo a su producto, el dinero local, y cuidar que cumpla su función; para ello debe velar por la estabilidad de los precios, sin la cual la moneda pierde su poder adquisitivo y deja de cumplir su función de valorización de bienes, produciendo, como consecuencia, un regreso al trueque o la sustitución de la moneda por otros medios de pago,

\footnotetext{
${ }^{42}$ Normalmente en casos de hiperinflación, el dinero pierde de tal forma su poder adquisitivo que se reduce frente a cada alza de inflación, que los agentes económicos dejan de utilizarlo y se cambian a otros medios de pago, aun cuando no sean medios de pago legales en el país, por ejemplo, se cambian a monedas "duras" como el dólar o el euro. Un paso paradigmático es la economía ecuatoriana, que el 9 de enero de 2000, el Presidente Jamil Mahuad anunció que se utilizaría el dólar estadounidense en lugar de la moneda local, el sucre. Los niveles de inflación anual a ese momento alcanzaban el $99 \%$ anual.
} 
como, por ejemplo, la moneda extranjera, que las autoridades locales no podrán controlar mayormente. Un buen ejemplo fue la crisis económica argentina de 2001, y la decisión de restringir la libre disposición de los depósitos bancarios, medida denominada coloquialmente como "corralito", que fue adoptada por decisión del gobierno del presidente Fernando de la Rua. Esta crisis condujo el uso masivo del dólar, y a que en algunos sectores se crearan medios de pago distintos a la moneda local, denominados "cuasi monedas", consistente principalmente en bonos provinciales y nacionales ${ }^{43}$.

En esta perspectiva, cabe preguntarse: ¿ podría un Banco Central no velar por el control de la inflación o la deflación? Estimo que si no lo hiciere vulneraría las reglas de la ciencia económica y dejaría de ser técnico en su actuar. Lo anterior no implica que sea obligación de un Banco Central velar porque no exista inflación, pues su obligación es cuidar la estabilidad de los precios y evitar sus fluctuaciones constantes que alteren el sistema de asignación de precios. ¿En qué punto de estabilidad? ¿ $1 \%$ o $15 \%$ ? Todo dependerá de su análisis técnico conforme con las distintas variables macroeconómicas que debe observar. Inflación no es lo mismo que la simple alza de precios, pues ella radica en el alza sostenida de precios (así como deflación es su baja sostenida); por consiguiente, la función técnica esencial del banco evitar esa alza sostenida.

Igualmente, un Banco Central debe preocuparse por el normal funcionamiento del sistema de pagos internos: dinero, cheques u otros y por el normal funcionamiento del sistema de pagos externos habida cuenta de que una economía está vinculada con mercados externos y es necesario pagar las importaciones, y proveer divisas, por ejemplo, a quienes desean retornar dinero a sus países de origen, para lo cual el retorno de las exportaciones proveen de medios de pago o divisas, que el Banco Central no puede emitir.

Por lo anterior, no es extraño que la LOCBCCh., en su artículo 3, haya establecido que: "El Banco tendrá por objeto velar por la estabilidad de la moneda y el normal funcionamiento de los pagos internos y externos ${ }^{44}$. ¿Podría técnicamente un banco central hacer algo distinto? ¿Sería un órgano técnico un banco central si propiciara la inestabilidad de la moneda o el mal funcionamiento del sistema de pagos?

${ }^{43}$ Argentina, luego de la crisis de 2001, alcanzó a tener 15 medios de pago, denominados "cuasi monedas" para diferenciarlos del peso argentino; y principalmente eran bonos provinciales y algunos nacionales. Por ejemplo: el "patacón” emitido por la Provincia de Buenos Aires, el "lecor" por la provincia de Córdoba o el "petrom" de la provincia de Mendoza. Las emisiones de estos bonos superaron los 7.600 millones de pesos argentinos al año 2002. Véase: SCHVARZER, Jorge, Bonos, cuasi monedas y politica económica, en Realidad Económica, 193 (2003) [disponible en http://www.iade.org.ar].

${ }^{44}$ Artículo 3 inciso $1^{\circ}$ de la Ley No 18.840 , orgánica del BCCh. 
Si un banco central realizara acciones como las que se proponen en aquellas interrogantes no sería un banco central que actúa de forma técnica. Si realiza esas acciones técnicamente inexplicables, se podrá inferir una motivación política coyuntural, que probablemente afectará gravemente la economía nacional, lo que en el caso chileno, además, constituiría una causal de remoción de los consejeros ${ }^{45}$, con lo cual estimo que la autonomía del BCCh. y sus consejeros tiene el límite de actuar técnicamente en sus funciones.

Si un Banco Central no tiene por giro u objeto precisamente velar por la estabilidad de la moneda y el normal funcionamiento de los pagos internos y externos, no tiene sentido; así que para cumplir adecuadamente su rol técnico necesita de autonomía política y patrimonial, y es por ello que estimo que en el carácter autónomo y técnico que le entrega la Constitución subyacen los objetivos que ha de cumplir el BCCh., ya que sin la búsqueda del cumplimiento de los mismos, hacen sin sentido el establecimiento del Banco y, más aun, tornan en un sin sentido su carácter técnico.

Por lo antes señalado, estimo que los objetivos del BCCh. establecidos en el artículo 3 de la LOCBCCh., naturalmente deben entenderse comprendidos en el texto constitucional, cuando define al BCCh. como un órgano técnico. Algunos, podrán contradecir esta opinión afirmando que si el constituyente hubiese querido señalar esos objetivos lo habría expresado derechamente. Por el contrario, creo que mencionarlos en el texto constitucional luego de definidos el carácter técnico y la autonomía, especialmente por la primera, hubiese sido redundante, sin que igual crítica se pueda hacer al texto de su ley orgánica, ya que precisamente su objeto es desarrollar la normativa constitucional. Por lo demás, el artículo 108 C.Pol. entrega a una ley orgánica constitucional la tarea de determinar la composición, la organización, las funciones y las atribuciones, pero no se dice ahí quedar entregado a la ley orgánica constitucional la fijación de su objeto o giro social, lo que solo puede entenderse en cuanto sus objetivos ya están definidos y comprendidos en el carácter técnico que le atribuye la Constitución.

La consagración constitucional del BCCh., además, complementa y apoya técnicamente el cumplimiento de sus objetivos, cuando el artículo 109

${ }^{45}$ Cabe recordar que el artículo 17 de la LOCBCCh. establece una causal de remoción de los consejeros que adopten acuerdos en contra del objeto del BCCh.: " $E l$ Presidente de la República, por causa justificada y previo consentimiento del Senado, podrá remover. Véase: a alguno o la totalidad de los miembros del Consejo. La remoción sólo podrá fundarse en la circunstancia de que el consejero afectado hubiere votado favorablemente acuerdos del Banco que impliquen un grave y manifiesto incumplimiento de su objeto, según lo define el inciso primero del articulo $3^{\circ}$, y siempre que dicho acuerdo haya sido la causa principal y directa de un daño significativo a la economia del pais". 
C.Pol. prohíbe otorgar su garantía a instituciones financieras, sean públicas o privadas; adquirir documentos emitidos por el Estado, sus organismos o empresas, y financiar ningún gasto público o préstamo con créditos directos o indirectos del BCCh. Sabido es que la principal fuente de inflación y de desconfianza en el sistema de pagos es el déficit fiscal, particularmente si ha sido financiado por el propio BCCh., situación que no puede ocurrir en Chile por prohibición constitucional.

El aporte que realiza la normativa constitucional al otorgar autonomía política y técnica, para evitar la inflación, lo destaca Andrés Bianchi, ex presidente del BCCh. entre los años 1989 y 1991, quien menciona la autonomía del Banco Central como presupuesto del control inflacionario: "La independencia del Banco Central constituye, probablemente, la innovación más valiosa introducida en nuestra institucionalidad económica en los últimos 20 años. En efecto, si se analiza la trayectoria histórica de la inflación chilena, resulta evidente que la autonomía del Banco marca un antes y un después" ${ }^{46}$.

\section{Un diseño constitucional destinado a facilitar el control de la inflación.}

El texto constitucional establee un conjunto de normas con contenido económico que, si bien asistemáticas en su ubicación en ese texto, en cuanto a su operatoria y aplicación conforman un sistema perfectamente integrado y coherente de reglas que buscan minimizar los problemas monetarios, merced a una restricción constitucional de las principales fuentes que históricamente favorecieron el crecimiento de la inflación, al menos desde el sector estatal.

En efecto, si bien la Constitución no ofrece un capítulo especial relativo al control financiero y económico de la actuación del Estado, lo que responde a una decisión del constituyente en orden a no crear un tal capítulo ${ }^{47}$, no es

${ }^{46}$ BIANCHI, Andrés, cit. (n. 28), p.11.

${ }^{47}$ Respecto de la decisión de establecer un capítulo especial referido al orden público económico, Raúl Bertelsen expresó en la Comisión de Estudio de la Nueva Constitución Política de la República (en Actas, sesión 388a, de 26 de junio de 1978, p. 2905): "Debe resolverse si se va a establecer o no en la Constitución un capitulo dedicado al orden público económico. Observa que en caso positivo deberá elaborarse una preceptiva ordenada, orgánica, encabezada por los principios básicos que se vayan desarrollando; y que si, en cambio, se establece a través del texto fundamental una serie de nociones congruentes relativas a materias de orden público económico, la tarea de la Comisión será más fácil, por cuanto se limitará a la revisión de ciertas normas constitucionales existentes o a la inclusión de algunas nuevas. Reitera su posición contraria a establecer dicho capitulo. Señala que de aceptarse su posición (contraria a establecer un capitulo especial), la tarea de la Comisión deberá concentrarse en los siguientes puntos: revisión del capitulo referente a las garantías constitucionales, precisión en la norma relativa al dominio máxima legal de las leyes que tengan incidencia económica, análisis sobre la posible creación con rango constitucional del 
menos cierto que la Constitución sí cuenta con una serie de normas de contenido económico, varias de las cuales tienen el claro objetivo de minimizar el desequilibrio fiscal, que se estima como principal fuente de desequilibrios macroeconómicos, particularmente consistentes en la inestabilidad de la moneda producida por un aumento de la masa monetaria no respaldada en un aumento de la producción sino sólo en un aumento de la deuda pública para financiar el déficit, ya que los gastos del Estado se cubren con deuda y no con sus propios ingresos.

Las normas que tienen este objetivo mantienen su redacción original desde el año 1980; y está permitido concluir que han cumplido cabalmente su función, a luz de los indicadores macroeconómicos que presenta el país, particularmente desde el año 1990 en adelante, esto es, desde la elección democrática del presidente de la República, de los parlamentarios y de la designación de los consejeros del BCCh. conforme con su ley orgánica constitucional que exige la intervención conjunta del presidente de la República y del Senado ${ }^{48}$. Desde ese momento, el diseño institucional constitucional transitó a completa aplicación. Por tanto, desde el año 1990 hasta el año 2010, ya se han completado dos décadas con índices de inflación bajo un dígito -bajo 10\%-. La excepción se experimentó en los primeros cuatro años, en que la inflación superó el 10\%; pero cabe considerar que el año 1990 la inflación alcanzó un 27,3\% para ya al año 1994 reducirse a un 8,9\%.

$\mathrm{Si}$ bien los indicadores macroeconómicos dependen del devenir económico, no es menos cierto que el devenir económico está sujeto a una institucionalidad que le entrega un marco de actuación a la economía, marco que cada país define democráticamente y lo hace normalmente en sus normas constitucionales. En el caso chileno, es posible apreciar un diseño de mecanismos que tienden al control del endeudamiento del Estado, y una protección al ejercicio de la política monetaria por parte de un órgano autónomo y técnico como define la Constitución al BCCh.

En teoría, es propio de la política fiscal que el Ejecutivo pueda hacer uso de los instrumentos de los impuestos y del gasto público para lograr los objetivos macroeconómicos que el mismo define. En el caso chileno, el diseño inicial de la política fiscal está limitado por la propia Constitución, favoreciendo el control monetario que realiza en Chile el BCCh. como se pasará a describir a continuación.

Consejo Monetario (en este sentido propicia la inclusión de un capitulo especial), y finalmente alusión a la justicia contenciosa-administrativa en lo referente al poder judicial".

${ }^{48}$ Salvo el primer Consejo, designado en el año 1989, por el presidente de la República, con acuerdo de la Junta de Gobierno, pero con base en una negociación política con la Concertación de Partidos por la Democracia. Sobre la negociación y designación de este primer Consejo, véase: BiANCHI, Andrés, cit. (n. 28), pp.15-17. 
a) Materias de ley. El artículo 63 No 7 C.Pol..$^{49}$ obliga al Estado, sus organismos y municipalidades a obtener una autorización legal para poder contratar empréstitos. Además, y a efectos de que estos empréstitos no terminen incrementando la masa monetaria sin respaldo ni pago, establece la Constitución que la propia ley autorizante deberá indicar el proyecto específico que se financiará con dicha deuda, lo que permite la focalización y control de ese gasto debiendo, además, señalar con cargo a qué fuente de recursos deberá realizarse el servicio de la deuda ${ }^{50}$.

Adicionalmente, si el servicio de la deuda excede la duración del respectivo período presidencial, la ley debe ser aprobada por quórum calificado, con lo que se evita que un nuevo gobierno deba asumir con una alta deuda fiscal, y si ésta existe lo será porque fue autorizada por un consenso mayor, como lo es el de una ley de quórum calificado. Cabe considerar que la mayoría de los empréstitos del Estado por las cuantías involucradas muy probablemente excederá el servicio de la deuda al período presidencial, por lo que la necesidad de quórum calificado para la ley autorizante puede transformarse en la regla general.

Esta norma, como las siguientes que mencionaremos, no se aplican al Banco Central atendido su propia naturaleza de institución cuya función esencial es otorgar crédito y endeudarse, por lo que si requiriera de una ley para cada endeudamiento sería inviable esa función; y, además, porque es un órgano autónomo.

${ }^{49}$ Artículo 63 No 7 C.Pol.: "Sólo son materias de Ley [...] o 7: Las que autoricen al Estado, a sus organismos y a las municipalidades, para contratar empréstitos, los que deberán estar destinados a financiar proyectos especificos. La ley deberá indicar las fuentes de recursos con cargo a los cuales deba hacerse el servicio de la deuda. Sin embargo, se requerirá de una ley de quórum calificado para autorizar la contratación de aquellos empréstitos cuyo vencimiento exceda del término de duración del respectivo periodo presidencial. Lo dispuesto en este número no se aplicará al Banco Central".

${ }^{50}$ Evitar la inflación limitando el endeudamiento estatal y particularmente prohibiendo que se financie esa deuda por el BCCh. ya que origina emisiones inorgánicas sin respaldo en el crecimiento económico, es una idea que subyace claramente en las actas de la Comisión de Estudios, cuando se discutieron los contenidos del orden público económico en la sesión 384, en la cual el fiscal del Banco Central, Roberto Guerrero, dijo [Actas de Comisión de Estudios, cit. (n. 37)]: "Propone dividir la materia en dos puntos: que el Estado en su actividad empresaria recibirá el mismo trato que los particulares, y que no podrá contratar préstamos directa o indirectamente con el Banco Central ni con cualquier otro organismo estatal. Agrega que también hay que agregar otras dos ideas, una de las cuales es que sólo en virtud de una ley podrá el Estado contratar préstamos, los cuales no podrán provenir del Banco Central, y otra, que deberán ser invertidos en los fines que la propia ley establezca. Añade que, por lo general, se tratará de proyectos cuyos recursos de financiamiento no se generan a corto plazo, por lo que un endeudamiento por ese lapso se traduciria en obligar al Banco Central a emitir, lo que genera inflación". 
El artículo 63 No 8 C.Pol. ${ }^{51}$ dispone que se requiere de una ley para autorizar la celebración de cualquier clase de operaciones que puedan comprometer en forma directa o indirecta el crédito o la responsabilidad financiera del Estado, sus organismos y de las municipalidades. Esta norma es clarísima respecto a buscar precaver y evitar que el Ejecutivo, de manera autónoma, comprometa el crédito o la responsabilidad financiera del Estado.

El artículo 63 № 9 C.Pol..$^{52}$ amplía la exigencia de habilitación legal para el financiamiento público a las empresas del Estado. Esta norma, al incorporar al Estado empresario a la reserva legal en materia de financiamiento busca evitar que dichas empresas incurran en endeudamiento sin habilitación legal previa y evita expresamente que se financien con el propio Estado.

Esta norma puede entenderse como discriminatoria para aquellas empresas del Estado que, llamadas a actuar en virtud del principio de subsidiariedad, esto es, cuando los particulares no pueden actuar, no quieren hacerlo o no lo hacen correctamente, ven restringido un aspecto importante de su gestión, ya que su política de financiación con el sector privado debe regularse previamente por ley, y le será aplicable todos sus controles, mientras, por otro lado, tienen inhibido su endeudamiento con el sector público, lo que contrasta con las empresas privadas que no tienen ninguna limitacion para obtener financiación en el sector privado y público. Por ejemplo, si entendemos que la empresa Correos de Chile cumple un rol subsidiario que justifica su existencia y actuación en el mercado, y por el desarrollo de la industria se incorporan empresas privadas de correos con las cuales debe competir-lo que debiere llevar a revisar si ha dejado de cumplir o no su rol subsidiario lo que es una discusión ajena a este trabajo-, dicha empresa estatal ve claramente limitada su capacidad y rapidez de gestión financiera al necesitar habilitación legal para financiarse con fondos ajenos y no poder además optar a financiamiento estatal, en circunstancia que su competencia no tiene limitaciones algunas para endeudarse incluso con el propio Estado. ${ }^{53}$

Una razón que vislumbro de esta discriminación constitucionalmente establecida para las empresas del Estado, que están habilitadas para operar

${ }^{51}$ Artículo 63 No 8 C.Pol.: "Sólo son materias de Ley [...] No 8: Las que autoricen la celebración de cualquier clase de operaciones que puedan comprometer en forma directa o indirecta el crédito o la responsabilidad financiera del Estado, sus organismos y de las municipalidades. Esta disposición no se aplicará al Banco Central".

${ }^{52}$ Artículo 63 No 9 C.Pol.: "Sólo son materias de Ley [...] No 9: Las que fijen las normas con arreglo a las cuales las empresas del Estado y aquellas en que éste tenga participación puedan contratar empréstitos, los que en ningún caso podrán efectuarse con el Estado, sus organismos o empresas".

${ }^{53}$ Véase: Guerrero BeCAR, José Luis, La libertad para desarrollar actividades económicas del artículo $19 N^{\circ} 21$ y la Constitución Económica, en Revista Persona y Sociedad, 4 (2000) 3, pp. 141-156. 
en el mercado conforme con las normas de los particulares, es pensar que se ha estimado que por sobre el principio de subsidiariedad se encuentra siempre el principio de equilibrio fiscal o, en otras palabras, que el principio de subsidiariedad y la necesidad de contar con la actividad empresarial del Estado no pueden significar en caso alguno que esta empresa no esté sujeta al principio de responsabilidad fiscal y que se le exige incluso mayor eficiencia que a una empresa privada, en cuanto debe considerar que su financiación no puede provenir de modo alguno de créditos del propio Estado.

Frente a la vulneración de estas normas y de los principios económicos contenidos en ella, operan los mecanismos de control establecidos por la Constitución, tales como el recurso de protección y el requerimiento al Tribunal Constitucional, el recurso de amparo económico y la vigilancia de la Contraloría General de la República. Sólo a efectos de ejemplificar, es posible mencionar uno de los casos más conocido de los últimos años, cual es aquel del préstamo otorgado por el Banco Interamericano de Desarrollo para financiar el proyecto de locomoción pública de superficie en la ciudad de Santiago, denominado Transantiago. El contrato omitió la habilitación legal previa. En este caso, el Tribunal Constitucional, por sentencia de fecha 30 de septiembre de 2008, declaró inconstitucional el Decreto Supremo No 45, del Ministerio de Transportes y Telecomunicaciones, de 16 de mayo de 2008, publicado en el Diario Oficial de 3 de junio del mismo año, mediante el cual se otorgan las autorizaciones previas exigidas por el inciso final del artículo $7^{\circ}$ de la Ley No $^{20.206}$, para que se contrate, con cargo a la Cuenta Especial de Reembolso, una línea de crédito de hasta cuatrocientos millones de dólares de los Estados Unidos de América, otorgada por el Banco Interamericano de Desarrollo. Dijo en el considerando No 83 lo siguiente: "Que, en consecuencia, al haberse aprobado un préstamo que compromete la responsabilidad financiera del Estado, en la forma que se ha demostrado en los considerandos que preceden, sin una ley que lo autorice, se vulnera el articulo 63, $N^{\circ} 8^{\circ}$, de la Constitución, y asi se declararán ${ }^{44}$

b) Iniciativa exclusiva del Presidente de la República en ciertas materias de ley. El artículo 64 C.Pol. establece las materias que son de iniciativa exclusiva del presidente de la República, por lo que de manera indirecta nos indica que las materias que menciona este artículo son materias de ley, ampliando el catálogo de reserva legal al relacionar este artículo con el artículo $63 \mathrm{~N}^{\circ} 1$ C.Pol.

Si se revisa el largo listado de materias que menciona este artículo, se incluyen casi todos los casos a través de los cuales un Gobierno puede rea-

${ }^{54}$ Véase la sentencia del Tribunal Constitucional, rol 1.153, de 30 de septiembre de 2008 [disponible en www.tribunalconstitucional.cl]. 
lizar una política fiscal mediante la utilización de herramientas de política económica fiscal, como son los impuestos y el gasto público, por ejemplo: materia de tributación, creación de empleos públicos, remuneraciones, emolumentos, montepíos, etc.

Lo anterior, salvo esta excepción que es curiosa desde el punto de vista económico: es materia de ley y de iniciativa exclusiva del presidente de la República fijar las remuneraciones mínimas del sector privado, lo que es absolutamente contradictorio con la visión monetarista, de acuerdo con la cual el mercado del trabajo es un mercado como cualquier otro, y que el precio de equilibrio debe ser fijado por el mercado mismo, ya que si el precio mínimo que fija el Estado está por sobre el de equilibro se producirá un exceso de oferta (las familias que ofrecen su trabajo), y consecuentemente una inhibición de la demanda por trabajo (empresas que no contratarán por estimar caro el servicio ofrecido).

Esta norma puede utilizarse como un argumento en favor de quienes estiman que no existe una preconcepción económica en el texto constitucional ${ }^{55}$; sin embargo, estimamos que es tal la fuerza de las restantes normas en el sentido o alineación con ideas monetaristas o neoliberales, que esta excepción cabe calificarla precisamente como tal, cuya inclusión se justifica por razones históricas (tal como también acaece con la propiedad estatal minera, que en los hechos vuelve a considerar la propiedad minera con participación privada a través de la Ley orgánica constitucional de concesiones mineras).

c) Normas de control presupuestario. El diseño constitucional de la Ley de presupuestos, desde una visión económica, constituye una herramien-

${ }^{55}$ Entre quienes estiman que en la constitución económica de la Constitución subyace no sólo una visión económica liberal respecto del Estado sino que subyacen las bases de un modelo económico neoliberal, véanse: BAUER, Carl, Derecho y economía en la Constitución de 1980, en Perspectivas, 2 (1998), 2 pp.23-47; Ferrada, Juan Carlos, La constitución económica de 1980. Algunas reflexiones críticas, en Revista de Derecho de la Universidad Austral, 11 (2000), pp. 47-53; Guerrero BeCar, José Luis, Regulación constitucional del orden económico. La experiencia chilena: Constitución Politica de la República de 1980, cit. (n. 8); Guerrero BeCar, José Luis, La libertad para desarrollar actividades económicas del artículo $19 N^{\circ} 21$ y la Constitución Económica, cit. (n. 53). Entre quienes estiman que en la constitución económica no subyace ningún modelo económico en particular sino que sólo parámetros generales axiológicos, como la libertad de empresa, véanse: BoRDALÍ, Andrés, Constitución económica y protección del medio ambiente, en Revista de Derecho de la Universidad Austral, 9 (1998), pp. 43-54; Fermandois Vöhringer, Arturo Derecho constitucional económico, Garantías económicas, Doctrina y Jurisprudencia (2a edición, Santiago, Editorial Pontificia Universidad Católica de Chile, 2006) I; Irarrazaval, Arturo, Principios económicos de la constitución de 1980, cit. (n.35). 
ta esencial para minimizar los desajustes presupuestarios, y particularmente evitar -aunque no eliminar- el déficit fiscal.

Lo anterior es fácilmente comprobable con la lectura del artículo 67 C.Pol., en el cual se observa la búsqueda de una política fiscal equilibrada o, más derechamente, que los gastos no superen la estimación de los ingresos proyectados para el período siguiente. Cabe tener presente que los gastos siempre se pueden ejecutar, mientras que los ingresos sólo se pueden estimar. He utilizado la expresión "período" y no "año", porque si bien es casi natural que la Ley de presupuestos sea anual, especialmente por la dificultad de proyectar ingresos por períodos más amplios, lo cierto es que la Constitución de 1980 nada dice respecto del período temporal que debe cubrir, a diferencia de lo que disponía expresamente la Constitución de $1925^{56}$, por lo que perfectamente se podría presentar un presupuesto a más largo plazo con déficit intermedios; pero es una costumbre asumida desde 1891 que la aprobación es anual ${ }^{57}$.

Conocido es que las dos principales herramientas de la política fiscal son los ingresos y el gastos público; y que éste, a su vez, puede ser gasto corriente, gasto de inversión o gastos de transferencias (subsidios). En la determinación, tanto de los ingresos como de los gastos que debe contener la Ley de presupuestos se aprecia un especial cuidado del constituyente para que exista un equilibrio de las cuentas internas del Estado. Dicho equilibrio es un objetivo macroeconómico que normalmente está vinculado con aquel de la estabilidad de la moneda, precisamente porque el primero es causa económica del segundo.

El artículo 67 C.Pol. dispone que el Congreso no podrá aumentar ni disminuir la estimación de ingresos; sólo podrá reducir los gastos contenidos en el proyecto, salvo los que están establecidos en alguna ley permanente. Reafirmando lo anterior, el inciso $3^{\circ}$ dispone que: "La estimación del rendimiento de los recursos que consulta la Ley de Presupuestos y de los nuevos que establezca cualquiera otra iniciativa de ley, corresponderá exclusivamente al Presidente, previo informe de los organismos técnicos respectivos". Con ello se evita que durante la tramitación del proyecto el Congreso pueda aumentar la

${ }^{56}$ Artículo 43 No 1 C.Pol. de 1925: "Son atribuciones exclusivas del Congreso: No 1: Aprobar o reprobar anualmente la cuenta de la inversión de los fondos destinados para los gastos de la administración pública que debe presentar el Gobierno, artículo 44 No 4 de la C.Pol. (Ch.). De 1925: Sólo en virtud de una ley se puede. No4: Aprobar anualmente el cálculo de entradas y fijar en la misma ley los gastos de la administración pública [...]”.

${ }^{57}$ La no aprobación del Congreso a la Ley de presupuestos de 1891 fue, como se sabe, el origen inmediato de la Guerra Civil que se produjo en Chile en 1891; por eso desde 1925 se estableció un plazo máximo para que el Congreso la apruebe, de modo que si no lo hace, rige el proyecto del presidente de la República. 
estimación de ingresos, por ejemplo, apreciar un valor de venta del cobre más alto, y con ello poder incorporar mayores gastos a la Ley de presupuestos.

Respecto de los gastos que contempla esta ley, el Congreso sólo puede reducir aquellos que presente el Presidente de la República, con lo que es claro que no puede aumentar esos gastos presentados por el ejecutivo; y si bien se le autoriza a incorporar nuevos gastos, lo que puede considerarse una vía para que el Congreso aumente el gasto público, inmediatamente la norma establece los controles que tienden a minimizar este efecto: Los nuevos gastos deben indicar con qué recursos se financiarán; y si la fuente de recursos que estimó el Congreso fuere insuficiente para financiar esos nuevos gastos, el presidente de la República, al promulgar la ley, previo informe favorable del servicio o institución a través del cual se recaude el nuevo ingreso, refrendado por la Contraloría General de la República, deberá reducir proporcionalmente todos los gastos, cualquiera que sea su naturaleza. Cabe resaltar que tal es una obligación constitucional del presidente de la República, ya que se utiliza la expresión "debe" y no "puede", por lo que su incumplimiento hace posible una acusación constitucional por infracción de la Constitución ${ }^{58}$.

Es este deber entregado al presidente de la República es la principal innovación de la Constitución en materia de Ley de presupuestos ${ }^{59}$ respecto de aquella de $1925^{60}$, que no proveía una herramienta semejante destinada efectuar el

${ }^{58}$ Artículo 48 No 2 letra a) C.Pol.

${ }^{59}$ Enrique Ortúzar, presidente de la Comisión de Estudios de la Nueva Constitución Política de la República, señala [Actas, cit. (n. 37), sesión 384a]: "Se ha reconocido al Primer Mandatario iniciativa legal exclusiva respecto de administración financiera y económica, remuneraciones, sistemas de seguridad social, impuestos, etcétera, y que se ha establecido el principio de que, si el Congreso despacha un proyecto no financiado, el Presidente de la República, con acuerdo de la Contraloría, puede limitar sus efectos a los recursos que realmente otorga, con lo que se evita lo que sucedió frecuentemente en el pasado de recurrir a emisiones inorgánicas". De esta cita es fácil advertir que no sólo existe una preocupación por el déficit fiscal sino por el problema monetario que conlleva al referirse a las emisiones inorgánicas.

${ }^{60}$ Artículo 44 No 4 C.Pol. de 1925: "Aprobar anualmente el cálculo de entradas y fijar en la misma ley los gastos de la administración pública. La ley de Presupuestos no podrá alterar los gastos o contribuciones acordados en leyes generales o especiales. Sólo los gastos variables pueden ser modificados por ella; pero la iniciativa para su aumento o para alterar el cálculo de entradas corresponde exclusivamente al Presidente de la República. El proyecto de Ley de Presupuestos debe ser presentado al Congreso con cuatro meses de anterioridad a la fech a en que debe empezar a regir; y si, a la expiración de este plazo, no se hubiere aprobado, regirá el proyecto presentado por el Presidente de la República. En caso de no haberse presentado el proyecto oportunamente, el plazo de cuatro meses empezará a contarse desde la fecha de la presentación. No podrá el Congreso aprobar ningún nuevo gasto con cargo a los fondos de la Nación, sin crear o indicar, al mismo tiempo, las fuentes de recursos necesarios para atender a dicho gasto". 
ajuste final de los gastos en relación a la estimación de ingresos. Con esta norma, se resguarda el equilibrio de la cuenta corriente y se evita la aprobación de cualquier gasto sin su respectivo financiamiento, lo que, consecuentemente, permite al gobierno enfrentar de mejor forma cualquier inestabilidad de precios, y al menos evitar constitucionalmente una de sus causas.

Refuerza el control presupuestario diseñado en la Constitución el capítulo $10^{\circ}$ sobre la Contraloría General de la Republica, cuyo artículo 100 establece: "Las Tesorerias del Estado no podrán efectuar ningún pago sino en virtud de un decreto o resolución expedido por autoridad competente, en que se exprese la ley o parte del presupuesto que autorice aquel gasto. Los pagos se efectuarán considerando, además, el orden cronológico establecido en ella y previa refrendación presupuestaria del documento que ordene el pago".

La idea de equilibrio fiscal que subyace en la norma constitucional de 1980, en la práctica se ha adoptado en la economía chilena como una herramienta, que más allá del mandato constitucional, se estima que permite dar estabilidad económica, es fuente de crecimiento y también de ahorro para enfrentar futuras crisis económicas.

Un buen ejemplo de lo señalado es el hecho que el propio Gobierno central desde el año 2001 se ha autoimpuesto la obligación de evitar los déficit fiscales mediante la aplicación de la denominada regla del su pe rávit estructural que consiste en mantener un superávit en el balance estructural en el Gobierno central consistente en un $1 \%$ del Producto Interno Bruto anual, regla que se redujo a un $0,5 \%$ en el año 2007 producto de la crisis financiera internacional -denominada sub prime-.

El balance estructural del Gobierno central muestra la situación del Fisco en una perspectiva de mediano plazo, en vez de su situación coyuntural, que es la que muestra su balance efectivo. El balance estructural implica estimar los ingresos fiscales que se obtendrían de manera aislada del ciclo económico y, consecuentemente, autorizar un gasto público coherente con dichos ingresos. En la práctica "esto se traduce en ahorros en tiempos de bonanza cuando se reciben ingresos que se sabe son sólo transitorios, justamente para poder gastarlos cuando se enfrentan coyunturas que hacen caer los ingresos o que hacen aumentar las necesidades de gasto" ${ }^{61}$.

${ }^{61}$ Véanse: Rodríguez Jorge - Tokman, Carla - Vega, Alejandra, Politica de balance estructural: Resultados y desafios tras seis años de aplicación en Chile, en Estudios de Finanzas Públicas (Santiago, Dirección de Presupuestos del Ministerio de Hacienda, 2006 [disponible en www.dipres.cl]; y Velasco, Andrés - Arenas, Alberto - RodríGUEZ, Jorge - JorRATT. Michael - GAMBONI, Cristóbal, Enfoque de balance estructural en la politica fiscal en Chile: Resultados, metodología y aplicación al periodo 2006-2009, en Estudios de Finanzas Públicas (Santiago, Dirección de Presupuestos del Ministerio de Hacienda, 2010) [disponible en www.dipres.cl]. 
Es necesario tener presente que no resulta posible garantizar un equilibrio fiscal con la sola promulgación de la Ley de presupuestos ya que los ingresos establecidos en ella responden a estimaciones que pueden verse no cumplidas por la coyuntura económica. En el caso chileno se consideran tres factores que influyen en los ingresos del Estado: la actividad económica, el precio del cobre y el precio del molibdeno. De esta manera, el balance estructural refleja el resultado financiero que hubiese tenido el Gobierno central en un año dado si el Producto Interno Bruto hubiese estado en su curso de tendencia y los precios del cobre y del molibdeno fuesen los de largo plazo.

Esta norma autoimpuesta por el Ministerio de Hacienda ha permitido al Estado de Chile ahorrar; y el ahorro financia la inversión y también permite -como ha sido el caso de Chile- enfrentar mejor los períodos de crisis económicas, tan propios de los ciclos económicos ${ }^{62}$.

En la misma perspectiva del control de gasto público, en el año 2006 se promulgó la Ley $\mathrm{N}^{\circ} 20.128$ sobre Responsabilidad fiscal que, entre otras materias, obliga al presidente de la República a establecer las bases de la política fiscal que será aplicada durante su administración y sus implicancias, y le obliga a informar sobre el estado estructural de las finanzas públicas y su impacto macroeconómico y financiero, así como sobre los pasivos contingentes del Fisco.

En materia de gasto público, una excepción a la aprobación previa merced a una ley, la establece la propia Constitución al disponer la posibilidad de ejecutar gastos no contemplados en situaciones de emergencia, lo que contempla en el artículo 32 No 20 C.Pol. La disposición constitucional establece, en primer término, el deber del presidente de la República de cuidar la recaudación de las rentas públicas y decretar su inversión con arreglo a la ley -con lo cual se elimina la discrecionalidad del gastos en cuanto requiere siempre de una habilitación legal, sin perjuicio de que ésta autorice la discrecionalidad.

${ }^{62}$ Sobre el superávit estructural, el ex presidente del BCCh., Bianchi, Andrés, cit. (n. 28), p. 22, señala: "El primero es plantear -de manera franca y clara- que el éxito histórico alcanzado en materia de estabilización no ha sido mérito exclusivo del Banco Central independiente que se estableció en diciembre de 1989. También decisivo en este logro ha sido el manejo, en general muy responsable, de la política fiscal. A diferencia de lo que sucedía en el pasado, cuando los cuantiosos déficit del Gobierno constituyeron la causa principal de la inflación, desde 1990 lo habitual ha sido la generación de saldos positivos en las cuentas públicas. Más aún: con la introducción en 2001 de la regla de superávit estructural, el monto del gasto público ha quedado vinculado al nivel de los ingresos permanentes del Gobierno, lo cual imparte a la política fiscal una positiva orientación estabilizadora y anticíclica. Esta ha sido reforzada, desde el año 2007, por la creación del Fondo de Estabilización Económica y Social y del Fondo de Reserva de Pensiones, en los cuales se ha acumulado la mayor parte de los recursos extraordinarios generados por la bonanza del cobre". 
No obstante lo anterior, se añade: "El Presidente de la República, con la firma de todos los Ministros de Estado, podrá decretar pagos no autorizados por ley, para atender necesidades impostergables derivadas de calamidades públicas, de agresión exterior, de conmoción interna, de grave daño o peligro para la seguridad nacional o del agotamiento de los recursos destinados a mantener servicios que no puedan paralizarse sin serio perjuicio para el pais".

Sin perjuicio de esta autorización del todo razonable, atendidas sus excepcionales causales, igualmente se establecen límites y prevenciones que tienden a limitar este gastos a sólo un dos por ciento del monto de los gastos que autorice la Ley de presupuestos, y establece responsabilidades solidarias y personales para las autoridades que ejecutarán estos gastos, si contravienen la Constitución ${ }^{63}$. Además, este decreto, denominado comúnmente "de emergencia" o "del $2 \%$ constitucional", debe ser tramitado ante la Contraloría General de la República, que en ningún caso le dará curso si los gastos decretados excedan el porcentaje señalado en la Constitución, caso en el cual deberá remitir copia íntegra de los antecedentes a la Cámara de Diputados ${ }^{64}$.

Durante la plena vigencia de la Constitución se utilizó este mecanismo para financiar el proyecto de locomoción pública de la ciudad de Santiago denominado Transantiago, luego de que el Tribunal Constitucional, en causa rol 1.153-2008, declararó inconstitucional el Decreto supremo $\mathrm{N}^{\circ}$ 45, de 2008, del Ministerio de Transporte y Telecomunicaciones, que autorizaba que un crédito con el Banco Interamericano de Desarrollo contara con garantía de CORFO, asumiendo un compromiso financiero el Estado de Chile y sus organismos, sin habilitación legal previa, y como no se pudo contar con esos recursos, se invocó la última frase habilitante del artículo 32 No 20 C.Pol.: agotamiento de los recursos destinados a mantener servicios que no pueden paralizarse sin serio perjuicio para el para el país ${ }^{65}$.

d) Contraloría General de la República y Tesorerías del Estado. El capítulo $10^{\circ}$ de la Constitución trata de la Contraloría General de la

\footnotetext{
${ }^{63}$ Artículo 32 No 20, parte final C.Pol.: "El total de los giros que se hagan con estos objetos no podrá exceder anualmente del dos por ciento (2\%) del monto de los gastos que autorice la Ley de Presupuesto. Se podrá contratar empleados con cargo a esta misma ley, pero sin que el item respectivo pueda ser incrementado ni disminuido mediante traspasos. Los Ministros de Estado of funcionarios que autoricen o den curso a gastos que contravengan lo dispuesto en este número serán responsables solidaria y personalmente de su reintegro, y culpables del delito de malversación de caudales públicos".

${ }^{64}$ Artículo 88 C.Pol.

${ }^{65}$ Los denominados "decretos de emergencia" estaban contemplados en la Constitución de 1925 desde el año 1943 -reforma constitucional Ley N ${ }^{\circ}$ 7.727-y el Gobierno que más los utilizó fundado en la causal de servicios cuya paralización producen serios perjuicios para el país, fue el del Presidente Salvador Allende, en 40 oportunidades.
} 
República, a la cual atribuye un carácter autónomo, lo que es una innovación en relación con la Constitución de 1925, que no la reconocía como un órgano con rango constitucional. La Constitución entrega a la Contraloría General de la República importantes atribuciones de control presupuestario, ya que debe velar por el control de la legalidad de los actos de la administración, fiscalizar el ingreso y la inversión de los fondos del Fisco, de las municipalidades y de los demás organismos y servicios que determinen las leyes; examinar y juzgar las cuentas de las personas que tengan a su cargo bienes de esas entidades y llevar la contabilidad general de la Nación.

El artículo 99 C.Pol. dispone expresamente que la Contraloría General de la República en ningún caso dará curso a los decretos de gastos que excedan el límite señalado en la Constitución y remitirá copia íntegra de los antecedentes a la misma Cámara. En cuanto a esos límites podemos encontrar dos casos: Los decretos de emergencia del $2 \%$ de los gastos de la ley de presupuestos, y precisamente los gastos previstos en la ley de presupuestos.

Refuerza esta preocupación constitucional de no autorizar pagos que excedan el límite del artículo 100 C.Pol. la norma que prescribe a las Tesorerías del Estado no ejecutar ningún pago sino en virtud de un decreto o resolución expedido por autoridad competente, en que se exprese la ley o la parte del presupuesto que autorice aquel gasto. Los pagos se efectuarán considerando, además, el orden cronológico establecido en ella y previa refrendación presupuestaria del documento que ordene el pago. Cabe destacar que esta norma sobre las Tesorerías del Estado, existía en el artículo 21 C.Pol. de 1925, pero sin aquella mención a la necesidad de efectuar el pago en orden cronológico y previa refrendación presupuestaria ${ }^{66}$ del documento que ordene el pago.

e) Banco Central de Chile. Como se señaló previamente, la Constitución reserva un especial capítulo $13^{\circ}$ al Banco Central de Chile, que es el corolario del diseño de la constitución económica chilena, en aquella parte que dice relación con el control de la inflación; y otorga al órgano emisor de dinero, pues, un carácter constitucional, autónomo y técnico, con prohibición constitucional de otorgar préstamos al Estado, pues una perspectiva monetarista ve en ello una de las principales causa de la inflación, como tantas veces hemos expresado.

En esa perspectiva, el artículo 109 C.Pol. dispuso expresamente: "Ningún gasto público o préstamo podrá financiarse con créditos directos o indirectos del Banco Central", lo cual constituye la manifestación más expresa del cambio de

${ }^{66}$ Real Academia Española, Diccionario de la Lengua Española cit. (n.v41), II, p.1.752 [también disponible en www.rae.es]: "Refrendar: Autorizar por medio de firma de persona hábil para ello”. 
visión económica en materia monetaria respecto de la situación previa a 1976, cuando se dicta en el año 1975 el Decreto-ley No 1.078 que disponía igual norma, pero sólo con rango legal, y que coincidió con el termino de períodos de alta inflación o hiperinflación como aquellos entre 1971 y 1975.

\section{Comentarios FINALES}

Desde el año 1976 Chile no presenta niveles de inflación que puedan ser catalogados como de hiperinflación y, desde el año 1990 al presente año 2010, sus niveles de inflación muestran una tendencia a la baja y con indicadores en promedio inferiores al $10 \%$.

Estos resultados han permitido una estabilidad monetaria, que es un elemento esencial para la consecución de otros objetivos macroeconómicos, como el crecimiento y el pleno empleo. En el mediano y largo plazo, una economía monetariamente estable debe generar crecimiento y éste, empleo.

De igual modo, en este período se han minimizado los períodos de déficit fiscal; más aún, ha sido una regla incluso autoimpuesta por el Ejecutivo tender al ahorro fiscal mediante la regla del superávit estructural.

Estos resultados se han producido bajo gobiernos de diversa tendencia político-económico: primero durante del Gobierno Militar, de visión neoliberal desde el año 1975; y luego, desde el año 1990, en gobiernos de la denominada Concertación de Partidos por la Democracia, que políticamente se puede clasificar como de centro-izquierda; y aún con mejores resultados en materia de control de la inflación y equilibrio fiscal que el Gobierno Militar. Para terminar el ciclo, durante el año 2010 los resultados han sido reiterados bajo un gobierno de derecha o centro-derecha, pues los niveles de inflación continúan estables y bajos, estimándose una inflación cercana al 4\%.

En el período 1980-2010 en análisis, el país ha enfrentado tres crisis económicas de importancia: La crisis de 1982, que afectó especialmente a la industria bancaria; la crisis asiática de 1997 y la crisis denominada “sub-prime" de 2008. Si se revisan las cifras, en la crisis de 1982 la inflación aumentó, y en las de 1997 y 2008 la inflación bajó o incluso fue negativa en el año 2009. ¿Qué sucedió?

Los hechos económicos mencionados no pueden analizarse de forma aislada con respecto al diseño normativo en materia económica, y creo que los niveles de inflación estable tienen una explicación, por cierto no única, pero sí muy importante, en hitos normativos: en 1975 se emitió el Decreto-ley No 1.078, que prohíbe al Banco Central otorgar préstamos al Fisco; en 1979, el Decreto-ley No 3.001 reafirmó esta prohibición; y el proceso culminó en el año 1980, con el establecimiento constitucional de la misma prohibición, complementado con una serie de otras normas constitucionales de contenido 
económico, que en su conjunto forman parte de la denominada constitución económica, que fijan cuatro ejes rectores de la materia: propiedad privada de los medios de producción, libertad de empresa, rol subsidiario del Estado y equilibrio financiero fiscal que contribuye a la estabilidad monetaria.

Este conjunto de normas constitucionales ha tenido un rol esencial en la minimización de los procesos inflacionarios, que en Chile históricamente estuvo vinculada al endeudamiento fiscal financiado con emisiones del BCCh. no respaldadas con un aumento de transacciones reales en la economía, y conductoras, por ende, a la elevación del endeudamiento fiscal y a la pérdida de poder adquisitivo de la moneda.

Es posible observar que durante el período 1980-1989 los niveles de inflación fueron fluctuantes, y que en períodos de crisis se privilegió el pleno empleo por sobre la inflación, que en caso alguno alcanzó aquellos niveles históricos previos. En los gobiernos del tiempo sucesivo, en cambio, el mismo fenómeno no se aprecia en los datos estadísticos, pues en él, el empleo normalmente ha estado por sobre la inflación. La explicación de estos hechos se puede vincular nuevamente con un hito normativo: el BCCh. es efectivamente autónomo sólo desde octubre de 1989, al promulgarse su ley orgánica-constitucional y comenzar a operar a los pocos meses su Consejo designado conforme con el mecanismo diseñado, que busca evitar que las designaciones queden ligas a un mismo gobierno ${ }^{67}$.

Por lo anterior, sin perjuicio de la propia convicción de los gobiernos, en orden a la bondad de una política económica dirigida a minimizar los déficit fiscales y a preservar una moneda estable, salvo la autorregulación impuesta por el Ministerio de Hacienda en el año 2001 al establecer la regla del superávit estructural, los resultados se explican en buena medida por el diseño constitucional económico, que coadyuva y orienta en orden a que limitan o derechamente prohíben las principales fuentes de emisión monetaria sin respaldo en la producción.

Ha sido, pues, la propia Constitución una de las principales causante de la estabilidad monetaria en Chile en los últimos 20 años. Como se ha tratado de demostrar en este trabajo, un análisis puramente económico del fenómeno monetario que prescinda del rol esencial que ha tenido el Derecho en la consecución del fenómeno de la estabilidad, es incompleto.

Sin desconocer, por cierto, el lugar que ocupan las políticas del BCCh. y las de austeridad fiscal, bien puede sostenerse que la estabilidad monetaria chilena también ha sido fruto de las normas constitucionales económicas, que han podido sustentar las políticas del banco y la conducta de austeridad fiscal.

${ }^{67}$ Véase: BiAnCHI, Andrés, cit. (n. 26). 
[Recibido el 2 de noviembre y aprobado el 2 de diciembre de 2010].

\section{BIBLIOGRAFÍA}

Bauer, Carl, Derecho y economía en la Constitución de 1980, en Perspectivas, 1 (1998) 2.

BiAnchi, Andrés, La autonomia del Banco Central de Chile: Origen y legitimación, en Revista Economía Chilena, 12 (2009) 3.

Bitar Chacra, Sergio, Chile 1970-1973, Asumir la historia para construir el futuro (Santiago, Pehuen, 1995)

Bordalí Andrés, Constitución económica y protección del medio ambiente, en Revista de la Derecho Universidad Austral, 9 (1998).

CÉspedes, Luis Felipe - VAldÉs, Rodrigo, Autonomía de Bancos Centrales: La experiencia chilena, en Documentos de Trabajo del Banco Central de Chile, 358 (2006).

De Gregorio, José, A veinte años de la Autonomía del Banco Central de Chile, en Economía Chilena, 12 (2009) 3.

Fermandois Vöhringer, Arturo, Derecho constitucional económico, Garantías económicas: Doctrina y Jurisprudencia ( ${ }^{\circ}$ edición, Santiago, Editorial Pontificia Universidad Católica de Chile, 2006).

FerRada Juan Carlos, La constitución económica de 1980. Algunas reflexiones críticas, en Revista de Derecho de la Universidad Austral, 11 (2000).

Ferrada, Juan Carlos, La autonomía del Banco Central: breve excurso de su contenido jurídico, en Gaceta Jurídica, 203 (1997) 2.

Ferrada, Juan Carlos, La autonomía del Banco Central: Reflexiones acerca de este modelo institucional de gestión de la politica monetaria, en Revista Chilena de Derecho, 30 (2003) 1.

Fontaine, Juan Andrés, Transición económica y Politica en Chile: 1970-1990, en Estudios Públicos, 50 (otoño de 1993)

García, José Francisco - Lima, Víctor, Derecho y Economia: Aire no te vendas, en RoSENDE, Francisco (editor), La Escuela de Chicago: Una mirada histórica a 50 años del convenio Chicago-Universidad Católica (2007, Santiago, Ediciones Universidad Católica de Chile).

Guerrero Becar, José Luis, La libertad para desarrollar actividades económicas del artículo $19 N^{\circ} 21$ y la Constitución Económica, en Revista Persona y Sociedad, 4 (2000) 3.

Guerrero Becar, José Luis, Regulación constitucional del orden económico. La experiencia chilena: Constitución Política de la República de 1980 (tesis de licenciatura, Valparaíso, Universidad Católica de Valparaíso, 1991).

Irarrázaval, Arturo, Principios económicos de la Constitución de 1980, en Revista Chilena de Derecho, 14 (1987).

Jовет, Julio César, El partido socialista de Chile (1 ${ }^{\text {a }}$ Edición digital, Santiago, Prensa Latinoamericana, 2003) [disponible en www.salvador-allende.cl/Biblioteca/ ps_jobet.pdf].

Mankiw, Gregory, Macroeconomía (6a edición, Barcelona, Bosch, 2007).

Muñoz Gomá, Oscar, Chile y su industrialización. Pasado, crisis y opciones, (Santiago, Cieplan, 1986). 
Piñera Echenique, Sebastián, Autonomía del Banco Central, en Revista de Derecho Público, 62 (2000).

Rodríguez Jorge - Tokman, Carla - Vega, Alejandra, Politica de balance estructural: Resultados y desafios tras seis años de aplicación en Chile, en Estudios de Finanzas Públicas (Santiago, Dirección de Presupuestos del Ministerio de Hacienda, 2006) [disponible en www.dipres.cl].

Rosende, Francisco (editor), La Escuela de Chicago: Una mirada a 50 años del convenio Chicago/Universidad Católica. Ensayos en Honor de Arnold C.Harberger (Santiago, Ediciones Pontificia Universidad Católica de Chile, 2007).

Rosende, Francisco, La autonomía del Banco Central de Chile: Una evaluación preliminar, en Cuadernos de Economía, 91 (1993).

Samuelson, Paul - Nordhaus, William, Economía (17a edición, Madrid, McGrawHill, 2002).

SCHVARZER, Jorge, Bonos, cuasi monedas y política económica, en Realidad Económica, 193 (2003) [disponible en http://www.iade.org.ar].

Valdés soublette, Juan Gabriel, La escuela de Chicago, operación Chile (Buenos Aires, Grupo Editorial Zeta .A., 1989).

Velasco, Andrés - Arenas, Alberto - Rodríguez, Jorge - Jorratt - Michael, Gamboni, Cristóbal, Enfoque de balance estructural en la politica fiscal en Chile: Resultados, metodología y aplicación al periodo 2006-2009, en Estudios de Finanzas Públicas (Santiago, Dirección de Presupuestos del Ministerio de Hacienda 2010) [disponible en www.dipres.cl].

Vergara, Pilar, Auge y caída del neoliberalismo en Chile (Santiago, FLACSO, 1985). 